\title{
An Identified Histaminergic Neuron Modulates Feeding Motor Circuitry in Aplysia
}

\author{
Hillel J. Chiel, ${ }^{1}$ Klaudiusz R. Weiss, ${ }^{*}$ and Irving Kupfermann $\dagger$ \\ Center for Neurobiology \& Behavior, The New York State Psychiatric Institute, New York, New York 10032, \\ Departments of †Physiology, *Anatomy and Cell Biology, and *†Psychiatry, ${ }^{*}+$ Columbia University College of \\ Physicians and Surgeons, and *School of Dental and Oral Surgery, New York, New York 10032
}

\begin{abstract}
An identified histaminergic neuron, C2, in the marine mollusk Aplysia is a complex mechanoafferent which appears to contribute to the maintenance of food arousal by means of its synaptic connections to the metacerebral cell (MCC). Because $\mathrm{C} 2$ also has extensive synaptic outputs to neurons other than the $\mathrm{MCC}$, we studied its possible motor functions. We identified several synaptic followers of $\mathrm{C} 2$ and found that some were excitatory motor neurons for extrinsic muscles of the buccal mass, while others were modulatory motor neurons that inhibited contractions. In addition, we found that these neurons and other synaptic followers of $\mathrm{C} 2$ received powerful inputs during feeding motor programs. In order to determine the functional significance of the synaptic outputs of $\mathrm{C} 2$, we studied extrinsic buccal muscles (E4 and E5) whose motor neuron (C6) is excited by $\mathrm{C2}$. Extracellular recordings from these muscles indicated that they receive input during swallowing and rejection, but not during biting movements. Lesions of these muscles, or of all extrinsic muscles, did not prevent animals from feeding, but decreased feeding efficiency, that is, the amount of seaweed an animal could ingest with each swallow. The data suggest that $\mathrm{C2}$ is an integrative proprioceptive cell that functions as a premotor neuron. The non-MCC synaptic outputs of $\mathrm{C} 2$ may reinforce the actions of the central feeding motor program. Specifically, C2 appears to aid the functioning of muscles that produce fine adjustments of the buccal mass and contribute to the efficiency of feeding behavior, rather than in producing gross movements.
\end{abstract}

Feeding behavior in Aplysia shares certain features common to motivated behaviors in higher animals (Bolles, 1967). First, feeding in Aplysia involves a number of different motor acts that must be appropriately patterned and smoothly coordinated (Kupfermann, 1974). Second, this behavior is powerfully modulated by a wide variety of internal and external conditions. For example, noxious stimuli or satiety can completely suppress feeding, whereas starvation or exposure to attractive food strongly facilitates feeding (Kupfermann and Pinskcr, 1968; Susswein et al., 1978).

In previous work (Weiss et al., 1978), we described a serotonergic neuron, the metacerebral cell (MCC), that appears to be specialized for modulating certain aspects of feeding behavior without itself playing a major rolc in patterning or coordination.

Received Oct. 22, 1985; revised Feb. 18, 1986; accepted Feb. 20, 1986.

We wish to thank Drs. T. J. Carew, V. F. Castellucci, R. D. Hawkins, E. R. Kandel, and J. Koester for their comments and discussions. This work was supported in part by PHS Grants MH35564, GM320099, and RSDA MH00304.

Correspondence should be addressed to Dr. I. Kupfermann, Center for Neurobiology \& Behavior, 722 West 168 th Street, Psychiatric Annex-8th floor, New York, NY 10032

'Present address: Bell Laboratories, 600 Mountain Avenue, Murray Hills, NJ 07974.

Copyright (C) 1986 Society for Neuroscience $0270-6474 / 86 / 082427-24 \$ 02.00 / 0$
The $\mathrm{MCC}$ is driven in part by input from an identified histaminergic neuron, C2 (Weiss et al., 1986a), which is a mechanoafferent (Weiss et al., 1986c) that is excited during the execution of feeding responses (Weiss et al., 1986b). C2 thus functions as an excitatory part of the afferent limb of a food arousal system in Aplysia. In addition, $\mathrm{C} 2$ has extensive synaptic output to numerous other neurons in the cerebral ganglion, especially those in the E cluster of the ganglion (McCaman and Weinreich, 1982, 1985; Ono and McCaman, 1980; Weinreich, 1977). In the present research, we attempted to further define the function of $\mathrm{C} 2$ by investigating the roles of its synaptic follower cells, other than the MCC. Specifically, we wished to explore 3 questions concerning the possible functions of $\mathrm{C} 2$ : (1) In addition to its sensory functions, does $\mathrm{C} 2$ act as a motor neuron via its peripheral axons? (2) Does $\mathrm{C} 2$ function as a premotor or command neuron that is part of the system that generates specific patterns of motor output? (3) In addition to its modulatory function expressed through the $\mathrm{MCC}$, does $\mathrm{C} 2$ have other modulatory actions on neurons resembling the $\mathrm{MCC}$ (i.e., on neurons that act on a relatively restricted range of behaviors), or does $\mathrm{C} 2$ have more general modulatory effects, consistent with its being an element of a central arousal system?

We present evidence that (1) $\mathrm{C} 2$ has no direct motor effects, (2) C2 can modulate the activity of its synaptic followers, which are activated during feeding motor programs, (3) C2 can, via its followers, modulate muscles associated with the buccal mass, and (4) the muscles that $\mathrm{C} 2$ modulates are active during feeding behaviors, and appear to contribute to the efficiency of swallowing. Thus, $\mathrm{C} 2$ may be a modulatory sensory neuron that acts on a set of muscles that do not have a major role in producing movements, but have a "platform" or "postural" function that improves the efficiency of feeding. Some of these results have appeared in a preliminary report (Chiel et al., 1982).

\section{Materials and Methods}

These experiments were done using Aplysia californica weighing 100$250 \mathrm{gm}$. Four types of preparation were used: the free-moving animal, a semi-intact (isolated head) preparation, a reduced preparation, and a simplified preparation.

The free-moving animal was implanted with extracellular electrodes, as described previously (Weiss et al., 1978). After the animal was anesthetized with $50 \% \mathrm{vol} / \mathrm{wt}$ isotonic magnesium chloride, an incision was made on its dorsal side at the level of the rhinophores and buccal mass, and the nerve or muscle of interest was cut and pulled into a short length of silastic tubing, into which the tip of a Teflon-insulated, platinumiridium wire (multistranded; Teflon coating, 0.005 in. in diameter; bare wire diameter, 0.0011 in.; Medwire Corp., Mt. Vernon, NY) was inserted. The electrode was tied to the nerve with a suture of 6-0 thread (Ethicon, Somerville, NJ) and a suture of 3-0 thread was tied as tightly as possible around the part of the tube into which the electrode was inserted. Another suture of 6-0 silk thread was tied less tightly around the other end of the tube, from which the nerve or muscle exited. The incision in the animal was sutured with 6-0 silk thread, and the animal 


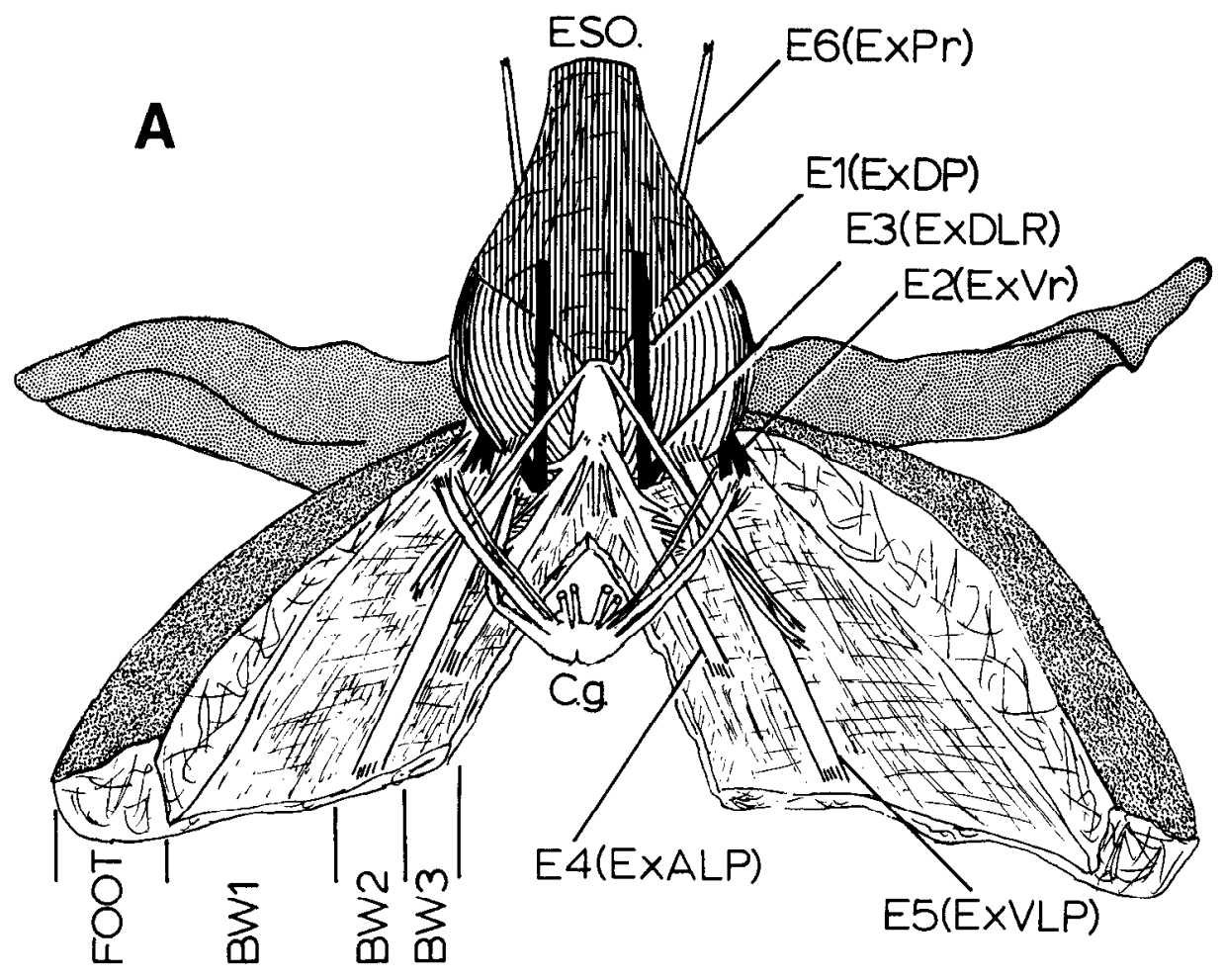

Figure 1. Gross anatomy of the body-wall muscles of the head and of the extrinsic muscles of the buccal mass. $A$, Semi-schematic representation of the reduced preparation. The dorsal surface is up, and the buccal mass has been rotated through an incision in the foot, in order to better reveal the extrinsic buccal muscles. The nerves from the cerebral ganglion have been omitted for the sake of clarity. The medial edge of body-wall muscle $1(B W 1)$ is continuous with body-wall muscle $2(B W 2)$, which, in turn, is continuous with body-wall muscle $3(B W 3)$. BW1 has a characteristic greenish coloration; BW2 is white; and BW3, which forms the top of the head, is slightly reddish in color. The extrinsic buccal muscles are indicated with the nomenclature we use, and by the nomenclature (in parentheses) used by Jahan-Parwar and Fredman (1983). Muscles E1 and E2 are reddish, while muscles E3,E4,E5, and E6 are white. C.g., Cerebral ganglion; ESO., esophagus. B, Dorsal (upper) and lateral (lower) views of the extrinsic muscles of the buccal mass, showing their approximate origins and insertions in the intact animal. $A T n$., Anterior tentacular nerve; $B . A$., buccal artery; $C . g$., cerebral ganglion; $P$-P.g., pedal-pleural ganglion; $S . g$., salivary gland; $U L n$., upper labial nerve. Drawings modified from those of Cuvier (1803).

was allowed to recover for $24 \mathrm{hr}$ before behavioral testing. Other animals were subjected to lesions of their extrinsic buccal musculature. After the animal was anesthetized with magnesium chloride, an incision was made on its dorsal side at the level of the rhinophores and buccal mass, and the extrinsic muscles were visualized. Unilateral or bilateral lesions of one or more muscles were made, the incision in the animal was sutured, and the animal was allowed to recover for $24 \mathrm{hr}$ before behavioral testing. Sham controls were anesthetized, a similar incision was made, the muscles were visualized but not cut, and the incision was sutured.

The semi-intact (isolated head) preparation, identical to that previously described (Weiss et al., 1986b), consisted of the isolated perfused head, connected to all of the ganglia of the animal.

$A$ reduced preparation (Fig. $1 A$ ) consisted of the cerebral and buccal ganglia, the anterior tentacles, mouth, jaws, and extrinsic buccal muscles, and the buccal mass. In order to clearly visualize the extrinsic buccal muscles that extend into the region around the mouth, the animal was dissected in the following way: It was pinned to a dissection dish with its ventral side facing up, and an incision was made through its foot. The esophagus was cut, the pedal-pleural ganglia removed, and the buccal ganglion was detachcd from the buccal mass, although it remained attached to the cerebral ganglion via the cerebral-buccal connectives. The buccal mass was then pulled through the incision in the foot, stretching the extrinsic muscles. Finally, the preparation was flattened by pinning out the tentacles and the buccal mass. Figure $1 \mathrm{~A}$ schematically illustrates the appearance of the muscles exposed by this dissection. Figure $1 B$ illustrates the appearance of the extrinsic buccal muscles in their normal positions. Contraction of individual muscles in the reduced preparation was monitored by a tension transducer (Bionix F-200) that was attached to the free end of the muscle by means of a small wire hook.
Simplified preparations consisted of either the isolated cerebral ganglion or the cerebral and buccal ganglia, interconnected by the cerebralbuccal connectives.

The semi-intact preparation was perfused with artificial seawater (ASW) and maintained at $16^{\circ} \mathrm{C}$. The other preparations were perfused with ASW maintained at room temperature.

In order to reduce spontaneous neuronal activity and decrease polysynaptic responses, in some experiments the preparation was perfused with a solution containing increased concentrations of divalent cations. Unless otherwise specified, this solution contained $3 \times$ normal $\mathrm{Ca}^{2+}(30$ $\mathrm{mm})$ and $3 \times$ normal $\mathrm{Mg}^{2+}(150 \mathrm{~mm})$.

Rhythmic motor programs were elicited either by means of food stimuli applied to the semi-intact preparation (as prevously described) or by electrical stimulation of the esophageal nerves in the reduced, semi-intact, and simplified preparations. Electrical stimulation of nerves was provided by a Grass 88 stimulator. In the semi-intact preparation, the esophageal nerve was stimulated by a bipolar hook electrode. In the other preparations, the esophageal nerve was stimulated by means of a polyethylene suction electrode.

In all preparations, the sheath over the cell groups from which intracellular recordings were made was removed. The recording-stimulating electrodes were double-barreled and were filled with $2 \mathrm{M}$ K-citrate. Single-barreled electrodes were sometimes used for impaling small cells. Tip resistances ranged from 5 to $15 \mathrm{M} \Omega$. Recording techniques were standard (Rosen et al., 1982).

Lucifer yellow (obtained from Walter Stewart and from Polysciences Corp.) was dissolved in distilled water ( $5 \% \mathrm{wt} / \mathrm{vol})$, filtered, and then used to fill single-barreled electrodes. The dye was injected using current pulses of 50 msec duration, with a duty cycle of $50 \%$ (Stewart, 1978). The tip resistance was continually monitored, and injection was stopped if it exceeded $100 \mathrm{M} \Omega$. 

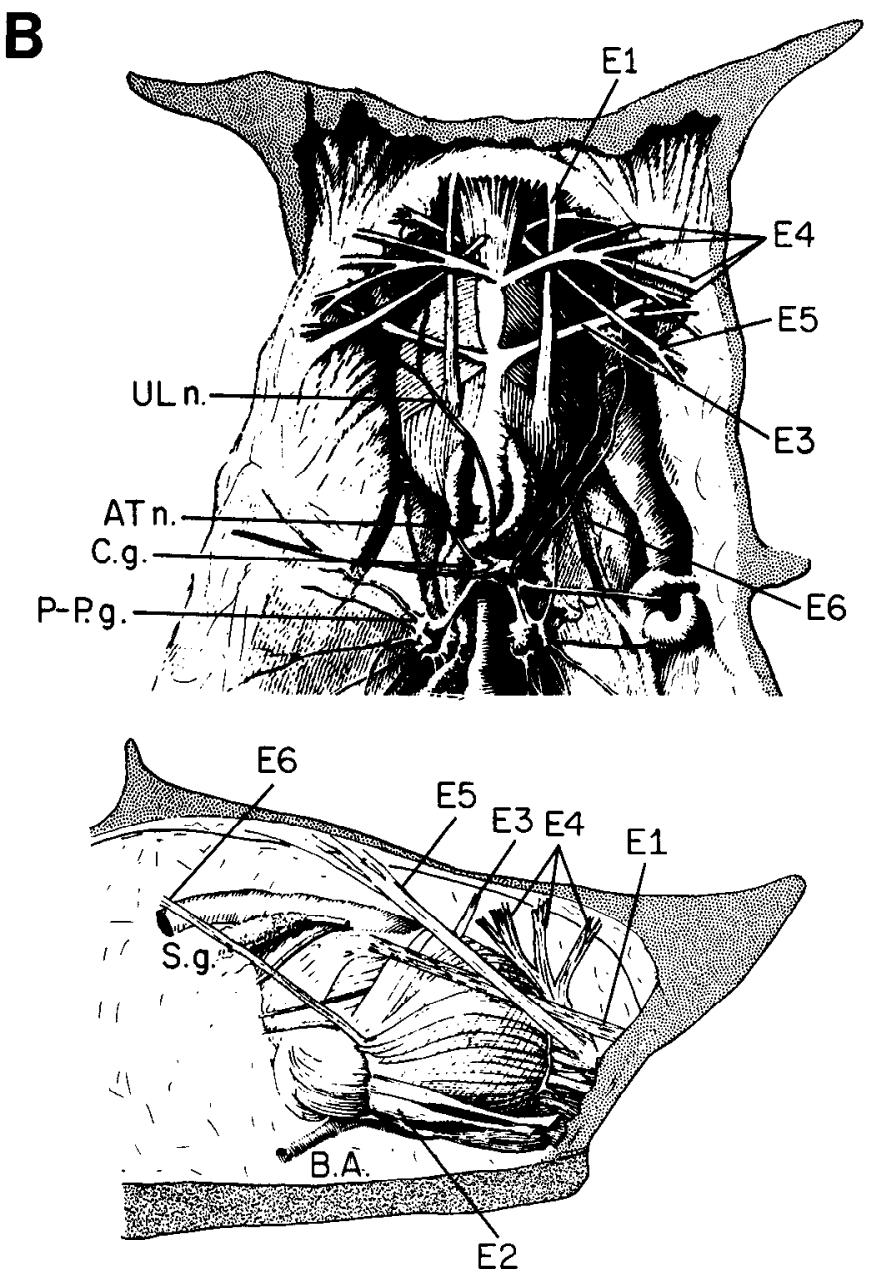

Figure 1. Continued

We were generally able to get excellent fills of small cells within 10$20 \mathrm{~min}$, but for large cells (over $100 \mu \mathrm{m}$ in diameter), it was generally necessary to switch electrodes and re-impale the cell $2 \times$ or more in order to get good results. Tissue was fixed in a 4\% paraformaldehyde/ $30 \%$ sucrose solution, cleared in glycerin, or dehydrated and cleared with methyl salicylate. Fluorescence was visualized using a Leitz fluorescence microscope.

\section{Results}

\section{A histaminergic cell can act via its followers to modulate motor outputs}

$C 2$ is not a motor neuron. Our previous studies showed that $\mathrm{C} 2$ could contribute to food arousal through its connections to the MCC, and that its peripheral axon branches could serve as sensory afferents (Weiss et al., 1986b, c). Since sensory neurons can also have direct motor effects (Beltz and Gelperin, 1980), we tested whether the peripheral axon branches of neuron $\mathrm{C} 2$ could serve a motor function. We identified $\mathrm{C} 2$ on the basis of (1) its size (80-100 $\mu \mathrm{m}$ in a $150 \mathrm{gm}$ animal); (2) its location (usually near the posterior edge of the E cluster; Fig. 2); (3) its appearance (unusually pale); and (4) its connection to the MCC (slow excitatory EPSP). Using the reduced preparation, we fired C.2 and observed various extrinsic buccal muscles, muscles of the mouth, and muscles of the tentacles and body wall. No reliable fixed-latency contractions of these muscles were found. However, firing $\mathrm{C} 2$ at high frequency did, on occasion, evoke motor responses, but these were inconsistent and had highly

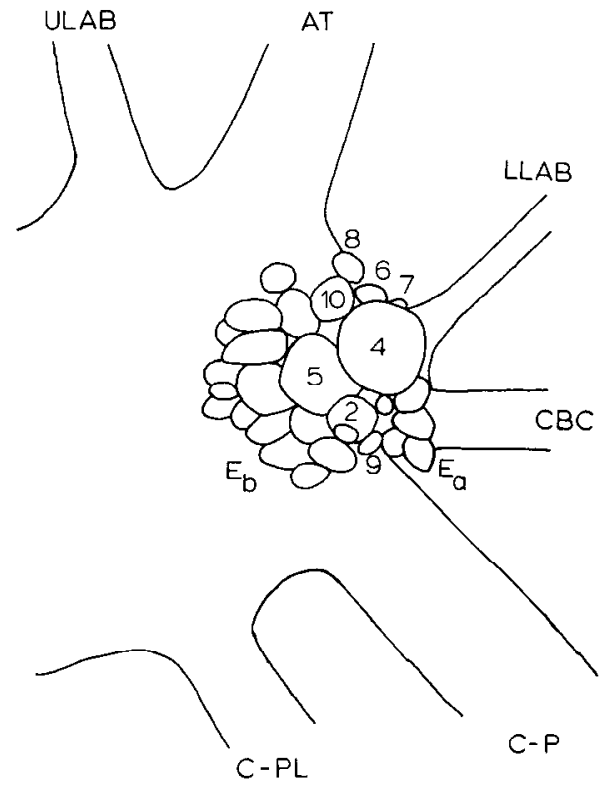

Figure 2. Schematic map of E cluster. This diagram of the right dorsal surface of the cerebral ganglion shows the approximate locations and relative sizes of various identified neurons. The size of the $E$ cluster relative to the rest of the ganglion has been exaggerated. $C 2$ is the histamine-containing neuron; $C 4-C 7$ are identified followers described in the text. $C 9$ is electrically coupled to $C 2$. $C 8$ is an inhibitory follower of $\mathrm{C} 2$, and is a putative motor cell for body-wall muscle that inserts into the ventral base of the buccal mass. C10 is not a follower of $\mathrm{C} 2$, but is a putative motor cell for body-wall muscle at the insertion of extrinsic muscle E3. $E_{a}$ is a cluster of cells that are inhibitory followers of $\mathrm{C} 2$, and are putative motor neurons for the mouth tissue; $E_{b}$ is a cluster of cells that are inhibitory followers of $\mathrm{C} 2$, and are putative motor neurons for the tentacles. Abbreviations (based on Jahan-Parwar and Fredman, 1976): $U L A B$, upper labial nerve; $A T$, anterior tentacular nerve; $L L A B$, lower labial nerve; $C B C$, cerebral-buccal connective; $C$ $P L$, cerebral-pleural connective; $C-P$, cerebral-pedal connective.

variable latencies. These results suggested that $C 2$ might activate contractions polysynaptically through its many synaptic connections in the cerebral ganglion. Results presented in later sections confirmed this conjecture.

Identified follower cells of $C 2$. In order to further pursue the possible functions of neuron $\mathrm{C} 2$, we set out to identify synaptic follower cells and to determine the possible functions of these cells. On the basis of previous studies of the synaptic effects of C2 (McCaman and Weinreich, 1982; Weinreich, 1977), we concentrated on cells in the E cluster (Fig. 2) of the cerebral ganglion (Jahan-Parwar and Fredman, 1976), a bilateral group of cells that contain the soma of $\mathrm{C} 2$. We studied the actions of individual neurons in the E cluster by firing them with depolarizing pulses and monitoring their effects on the movement of various muscles (either visually or by means of a strain gauge). We found that cells in the E cluster caused movements of the extrinisic muscles of the buccal mass, lips, mouth, tentacles, or body wall (Fig. 2). Firing $\mathrm{C} 2$ evoked excitatory and inhibitory responses in a large number of cells in the E cluster, as McCaman and Weinreich have described $(1982,1985)$. We were able to reliably identify 3 excitatory followers (C4, C5, and $\mathrm{C} 6)$, and one inhibitory follower (C7).

Iwo of the excitatory followers, C4 and C5, were the largest and second largest cells in the E cluster. Both cells received slow excitatory input from $\mathrm{C} 2$. The two cells, however, were readily differentiated on the basis of their relative sizes and the nature of their slow EPSPs.

Cell $\mathrm{C} 4$ is generally the larger of the 2 cells, and receives an unconventional EPSP resembling that evoked by $\mathrm{C} 2$ in the $\mathrm{MCC}$. 
Figure 3. $\mathrm{C} 2$ induces a slow EPSP in identified neuron C4. $A_{l}$, Firing $\mathrm{C} 2$ increased the firing rate of $\mathrm{C} 4$ when $\mathrm{C} 4$ was at resting potential. $A_{-4}$, As neuron $C 4$ was hyperpolarized 10,40 , and $60 \mathrm{mV}$ relative to resting potential, the EPSP induced by $\mathrm{C} 2$ reduced in size but did not reverse. Fast small EPSPs in C4 may be due to polysynaptic activity induced by firing $C 2$ because they are not one-for-one with spikes in $\mathrm{C} 2$. Note that the $\mathrm{C} 4$ trace is at a higher gain than in section $A_{i}$. $B_{l}$, Firing C2 induced a slow EPSP in neuron $C 4$ when the ganglion was bathed in artificial seawater $(A S W)$. $B_{2}$, Firing $\mathrm{C} 2$ continued to induce a slow EPSP in C4 when the ganglion was bathed in a $3 \times \mathrm{Ca}^{2+}, 3 \times \mathrm{Mg}^{2+}$ solution
$A_{1}$

RESTING POTENTIAL

C4

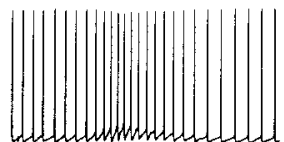

C4

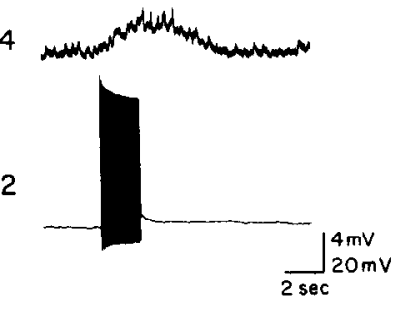

$A_{2}$

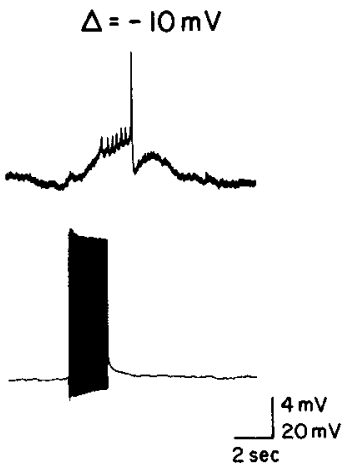

$A_{4}$

$\Delta=-60 m V$

$\mathbf{B}_{\mathbf{1}}$

ASW
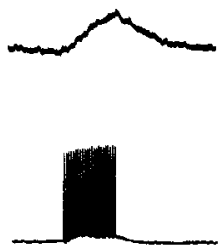

$\mathrm{B}_{2}$

$3 \times \mathrm{Ca}^{2+}, 3 \times \mathrm{Mg}^{2+}$

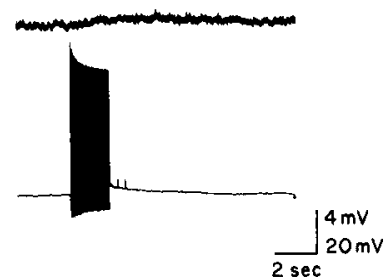

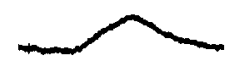

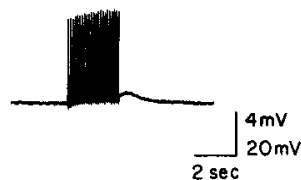

This EPSP diminishes as $\mathrm{C} 4$ is hyperpolarized (Fig. $3 A$ ). Although hyperpolarization reduces the EPSP to $0 \mathrm{mV}$, it does not reverse, even when $\mathrm{C} 4$ is hyperpolarized to $120 \mathrm{mV}$, well beyond the potassium equilibrium potential. During this slow EPSP, the conductance of $\mathrm{C} 4$, measured by constant current

pulses, is little changed or decreases. The EPSP due to firing of $\mathrm{C} 2$ persists relatively unchanged when the ganglion is bathed in a solution of high divalent cations (Fig. $3 B$ ), which suggests that the connection between $\mathrm{C} 2$ and $\mathrm{C} 4$ may be monosynaptic. We further characterized $\mathrm{C} 4$ by injecting it with Lucifer yellow. $\mathrm{C} 4$

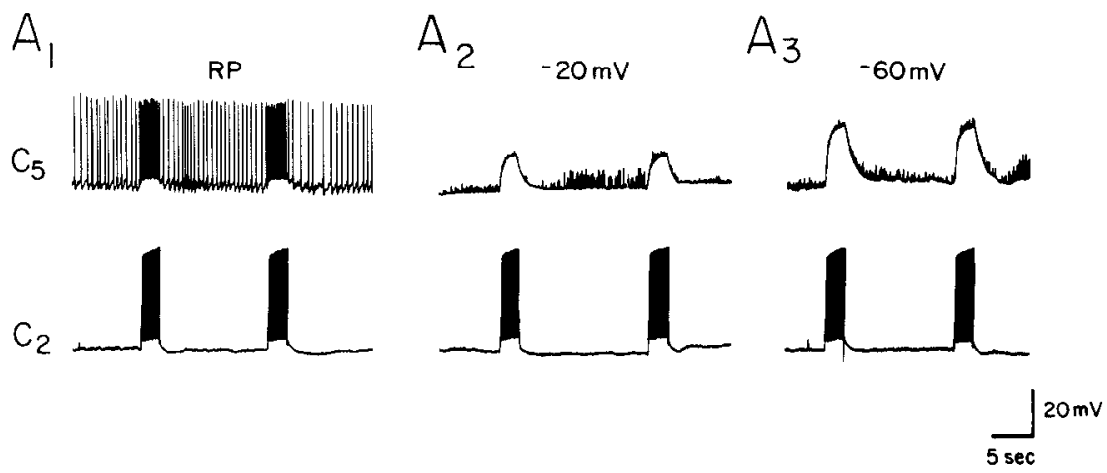

Figure 4. C2 induces a decreased conductance EPSP in identified neuron $\mathrm{C} 5$. $A_{1}$, Firing $\mathrm{C} 2$ increased the firing rate of $\mathrm{C} 5$ when $\mathrm{C} 5$ was at resting potential. $A_{2,3}$, Hyperpolarizing $\mathrm{C} 5$ 20 and $60 \mathrm{mV}$ relative to resting potential increased the size of the EPSP induced by firing $\mathrm{C} 2$. $B$, Total membrane conductance (plotted in top trace) of $\mathrm{C} 2$ was estimated by means of brief intracellular constant current pulses. Firing of $\mathrm{C} 2$ resulted in an increased conductance in $\mathrm{C} 5$, as reflected in a decrease in the size of the constant current pulses.

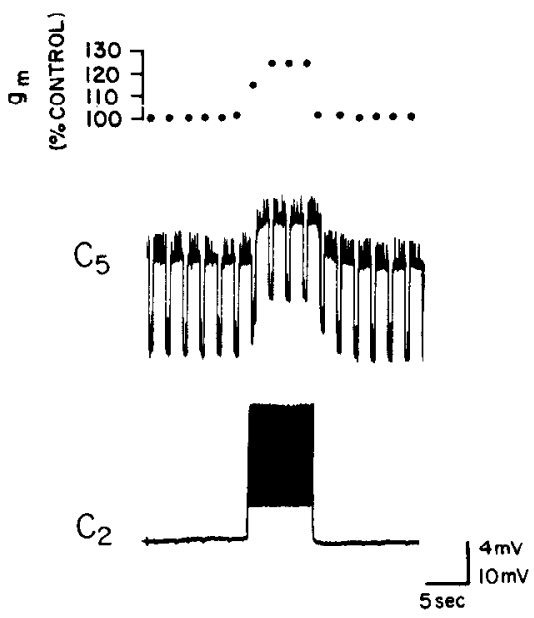


A

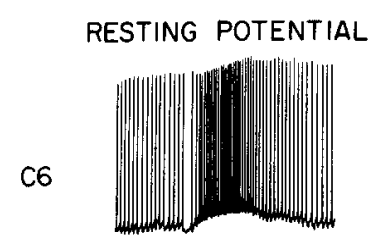

$B_{1}$

$$
\Delta=-20 \mathrm{mV}
$$
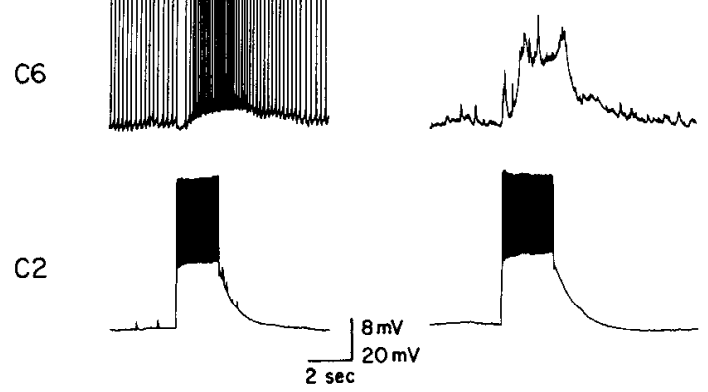

$C_{1}$

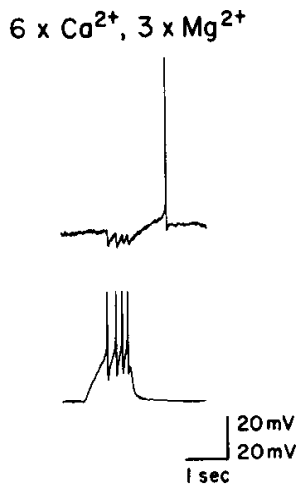

$\mathrm{C}_{2}$
$\mathrm{B}_{2}$
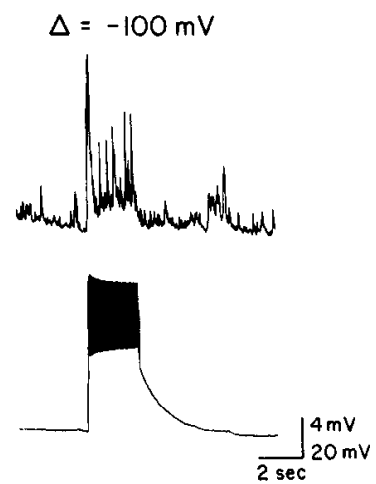

Figure 5. C2 induces a fast IPSP, slow EPSP in identified neuron C6. $A$, Effect of $\mathrm{C} 2$ on activity of $\mathrm{C} 6$ when C6 was at its resting potential. Note fast inhibition, slower excitation of $\mathrm{C} 6$, which outlasts the firing of $\mathrm{C} 2$. $B$ Same preparation as in $A$. Effect of $C 2$ on potential of $\mathrm{C} 6$ as $\mathrm{C} 6$ was hyperpolarized 20 and $100 \mathrm{mV}$ relative to resting potential. Note that the early fast IPSPs reversed and increased in size. The slower depolarization decreased in size, but did not reverse, while polysynaptic fast PSPs increased in size. $C_{l}$, Another preparation illustrating synaptic effects of $\mathrm{C} 2$ on $\mathrm{C} 6$. Firing neuron $\mathrm{C} 2$ induced fast IPSPs and a slower EPSP in C6 in a $6 \times \mathrm{Ca}^{2+}, 3 \times \mathrm{Mg}^{2+}$ solution, suggesting that the connection is monosynaptic. $C_{2}$, Same data as in $C_{l}$, but at a higher gain and a faster sweep speed.

has 2 periphcral axons, onc in the upper and one in the lower labial nerve. These nerves innervate the lips, the tentacles, and the extrinsic muscles of the buccal mass. Firing $\mathrm{C} 4$ did not produce contractions. We found, however, that it could modulate contractions (see below).

In contrast to that of $\mathrm{C} 4$, the EPSP produced by $\mathrm{C} 2$ onto cell
C5 behaves as if it were due to an increase of membrane conductance. The EPSP increases in size when C5 is hyperpolarized, and decreases when $\mathrm{C5}$ is depolarized (Fig. $4 A$ ). Furthermore, during this EPSP, the conductance of $C 5$, measured by constant current pulses, increases (Fig. $4 B$ ). The EPSP also persists in a solution of high divalent cations, suggesting that the connection

Table 1. Identifying characteristics of neurons in the $\mathbf{E}$ cluster

\begin{tabular}{|c|c|c|c|c|c|c|}
\hline $\begin{array}{l}\text { Neuron } \\
\text { or group }\end{array}$ & Input from $\mathrm{C} 2$ & $\begin{array}{l}\text { Input }{ }^{a} \text { from } \\
\text { buccal ganglion }\end{array}$ & Size & Motor action & Other name ${ }^{b}$ & Other action ${ }^{b}$ \\
\hline $\mathrm{C} 2$ & - & s, f IPSP & $\mathbf{M}$ & Indir. & E3 & None des. \\
\hline $\mathrm{C} 4$ & $\begin{array}{l}\text { Cond. dec. } \\
\text { s EPSP }\end{array}$ & large f EPSP & $\mathrm{L}$ & Inhib. E4, E5, BW1 & E1 & $\begin{array}{l}\text { Exc. ExVr [E2]; } \\
\text { inh. ExVLP [E5] }\end{array}$ \\
\hline C5 & $\begin{array}{l}\text { Cond. inc. } \\
\text { s EPSP }\end{array}$ & large f EPSP & $\mathrm{L}$ & None obs. & E2 & Inh. ExVLP [E5] \\
\hline $\mathrm{C} 6$ & $\begin{array}{l}\text { f IPSP } \\
\text { f EPSP, s EPSP }\end{array}$ & large f IPSP & $\mathbf{S}$ & Exc. E4, E5 & E6 & Exc. ExVLP [E5] \\
\hline C7 & s IPSP & s IPSP & S & Exc. BW1 & - & \\
\hline $\mathrm{C} 8$ & s IPSP & $?$ & $\mathbf{S}$ & Exc. BWA & - & \\
\hline $\mathrm{C} 9$ & Elec. coup. & $?$ & $\mathbf{S}$ & None obs. & - & \\
\hline $\mathrm{Cl}$ & No input & $?$ & $\mathbf{M}$ & Exc. BWB & - & \\
\hline $\mathrm{E}_{\mathbf{a}}$ & s IPSP & $?$ & $\mathbf{S}$ & Exc. mouth tissue & - & \\
\hline$E_{b}$ & s IPSP & $?$ & $\mathbf{S}$ & Exc. tent. tissue & - & \\
\hline
\end{tabular}

Abbreviations and symbols: $\mathbf{S}=$ small; $\mathbf{M}=$ medium; $\mathbf{L}=$ large; $\mathrm{s}=$ slow PSP; $\mathrm{f}=$ fast PSP; cond. dec. = conductance decrease; cond. inc. $=$ conductance increase; des. = described; indir. = indirect; exc. = excites; inh. = inhibits; obs. = observed; elec. coup. = electrically coupled; $-=$ not applicable; ? = not known; BWA = bodywall muscle at ventral base of buccal mass; $\mathrm{BWB}=$ body-wall muscle at base of extrinsic muscle E3.

${ }^{a}$ Buccal inputs to cerebral cells described in column 2 are based on data from the semi-intact (feeding head) preparation and from activity in isolated cerebral-buccal ganglia during stimulation of the esophageal nerve.

${ }^{b}$ The alternative names and actions of E cluster neurons are based on the publication of Jahan-Parwar and Fredman (1983). Note that they name neurons with an "E" prefix, whereas we use the E prefix to name muscles (both in "Motor action" column, and in brackets in "Other action" column).

' Jahan-Parwar and Fredman felt that their neuron E5 might be the histaminergic neuron C2, but we assign C2 to their neuron E3 based on its location on their map of the $\mathrm{E}$ cluster, and the properties they report for their neuron E5. 
A

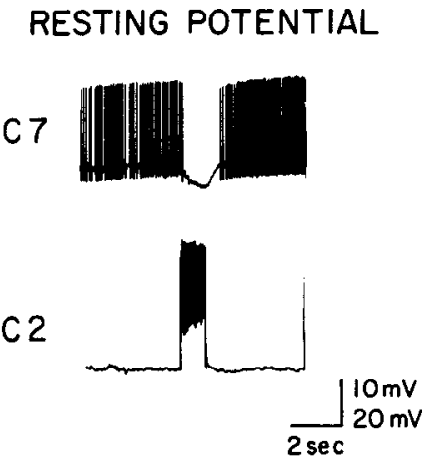

C

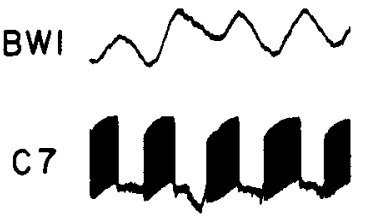

C2

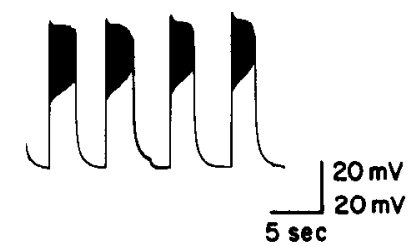

$B_{1}$

$\Delta=-20 \mathrm{mV}$
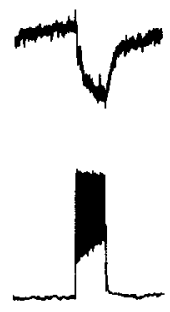

$B_{2}$
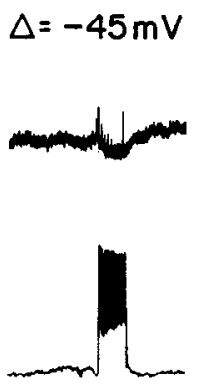

$B_{3}$
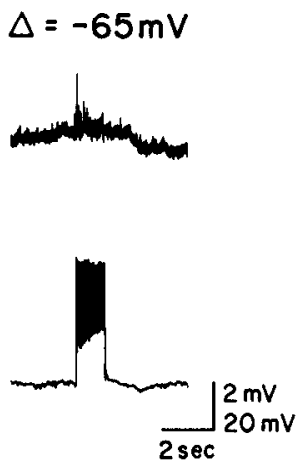

$D_{1}$

BWI

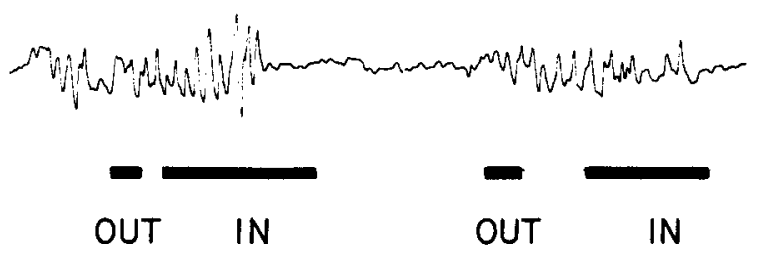

$D_{2}$

BWI

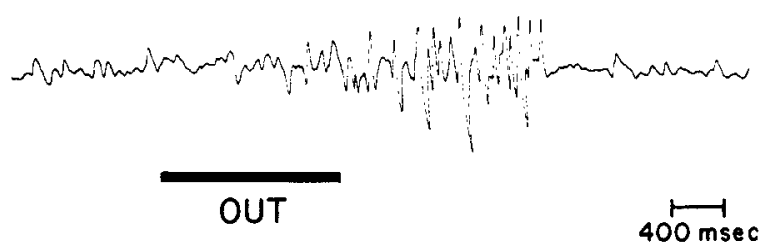

Figure 6. $\mathrm{C} 2$ induces a slow IPSP in identified neuron $\mathrm{C} 7$. Neuron $\mathrm{C} 7$ causes the contraction of body-wall muscle BW1, which is active during feeding behavior. $\mathrm{C} 2$ can relax muscle BW1 through its connections to $\mathrm{C} 7$. $A$, Firing $\mathrm{C} 2$ inhibited the firing of $\mathrm{C} 7 \mathrm{when} \mathrm{C} 7$ was at resting potential. $B$, As C7 was hyperpolarized 20,45 , and $65 \mathrm{mV}$ relative to resting potential, the IPSP induced by $C 2$ became smaller. $C$, Firing C7 caused contractions of body-wall muscle BW1. Firing C2 inhibited $\mathrm{C} 7$ and caused the muscle to relax. Tension in BW1 was monitored with a strain gauge. $D_{l}$, Extracellular potentials in BW1 in the intact, behaving animal recorded with an electrode implanted into the muscle. The record was obtained as the animal swallowed a $0.5 \times 5 \mathrm{~cm}$ strip of seaweed. Bars below the record indicate the observed movements of the seaweed strip. $D_{2}$, Recordings of rejection responses from the same animal as in $D_{l}$. Animal was induced to swallow a length of silastic tubing by stimulating its lips with seaweed. After several swallows, the animal began to reject the tube. The bar below the record indicates the observed movement of the tube.

between $\mathrm{C} 2$ and $\mathrm{C} 5$ is monosynaptic. Injection of $\mathrm{C} 5$ with Lucifer yellow revealed that it has a peripheral axon in the upper labial nerve. Firing C5 did not produce contractions.

The third excitatory follower, cell $\mathrm{C} 6$, is much smaller than $\mathrm{C} 4$ or $\mathrm{C5}$, and is usually located adjacent to $\mathrm{C} 4$ (see Fig. 2). It receives a compound synaptic potential from $\mathrm{C} 2$ : a fast IPSP, followed by a slow EPSP (Fig. $5 A$ ). The fast IPSP can be inverted by hyperpolarizing $\mathrm{C} 6$, while the slow EPSP diminishes in size but does not reverse as $\mathrm{C} 6$ is hyperpolarized (Fig. $5, B_{1}, B_{2}$ ). Both PSPs persist in a solution of high divalent cations (Fig. $\left.5, C_{1,2}\right)$. C6 can be further distinguished from other follower cells since it evokes a short-latency contraction of extrinsic buccal muscles E4 and E5 (see next section).

Though the histaminergic neuron $\mathrm{C} 2$ has many inhibitory followers in the E cluster of the cerebral ganglion, only one (C7) could very readily be located and impaled. $\mathrm{C} 7$ is similar to $\mathrm{C} 6$ in size (small) and location (adjacent to C4; Fig. 2). It receives a slow IPSP from $\mathrm{C} 2$, which diminishes as $\mathrm{C} 7$ is hyperpolarized (Fig. 6, $A, B$ ). C7 could also be distinguished by its ability to cause a powerful contraction of a body-wall muscle (see next section). Other neurons that we have identified in the E cluster include $\mathrm{C} 10$, a medium-sized neuron that, when fired, causes a contraction of the body wall near the insertion of extrinsic muscle $\mathrm{E} 3$; $\mathrm{C} 9$, a small neuron that is electrically coupled to $\mathrm{C} 2$; and $\mathrm{C} 8$, a small neuron that is inhibited by $\mathrm{C} 2$, and which, when fired, causes contractions of the body wall near the ventral base of the buccal mass. These neurons have not been studied in detail. In addition to the neurons that could be identified as uniquely individual, we identified 2 clusters of inhibitory followers of $C 2$. The $E_{a}$ cluster is located laterally in the $E$ cluster (Fig. 2) and contains neurons that, when fired, cause movements of the tissue around the mouth. The $\mathrm{E}_{\mathrm{b}}$ cluster is located medially and contains neurons that, when fired, cause movements of the tentacles.

In our experience, for most neurons in the cerebral ganglion, multiple criteria must be used for reliable identification. A particularly useful identifying characteristic for neurons in the $\mathrm{E}$ cluster is the nature of their motor effect, combined with a description of the type of synaptic connection they receive from the identified histaminergic neuron $\mathrm{C} 2$. Table 1 summarizes the neurons and cell groups we have identified in the E cluster and, where possible, compares the data to those of Jahan-Parwar and Fredman (1983). A report of McCaman and Weinreich (1982) presents a map of the cerebral E cluster and indicates the nature of a number of connections of neuron C2. Their map, however, does not give any indication of the connection of $\mathrm{C} 2$ to either 

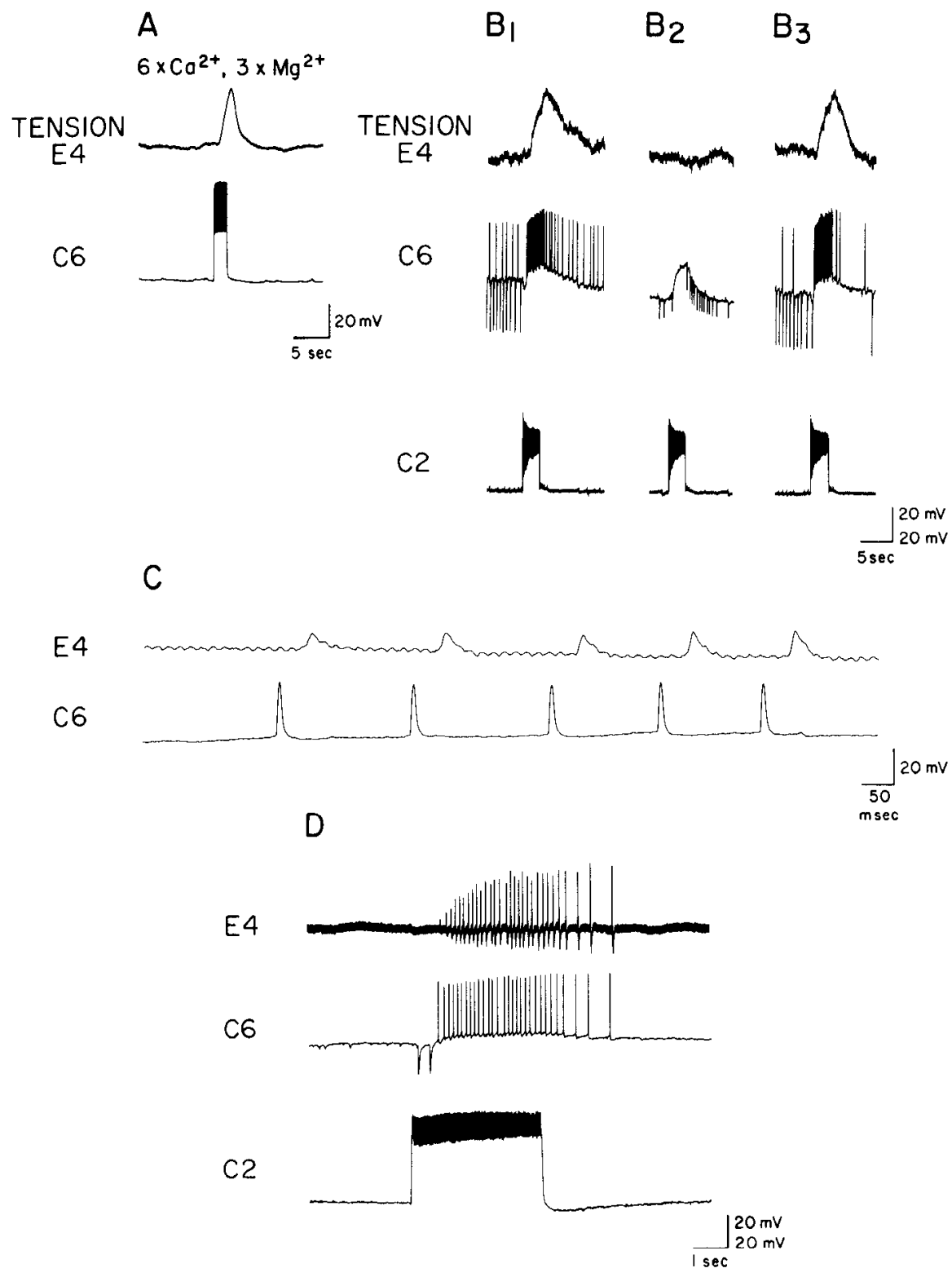

Figure 7. C6 induces extracellular junction potentials in, and contractions of, extrinsic buccal muscle E4. $\mathrm{C} 2$ can activate muscle $\mathrm{E} 4$ through its connections to $\mathrm{C} 6$. $A$, Firing $\mathrm{C} 6$ caused an increase in the tension of muscle E4 when both the ganglion and the muscle were bathed in a $6 \times \mathrm{Ca}^{2+}$, $3 \times \mathrm{Mg}^{2+}$ solution, suggesting that the effect of $\mathrm{C} 6$ was monosynaptic. $B, \mathrm{C} 6$ was slightly depolarized. Firing $\mathrm{C} 2$ further depolarized C6, causing E4 to contract. Note suppression of the IPSP. $B_{2}$, Same preparation as $B_{l}$. C6 was hyperpolarized, and firing $\mathrm{C} 2$ had no direct effect on E4. $B_{3}$, the effect of $\mathrm{C} 2$ on $\mathrm{E} 4$ reappeared when $\mathrm{C} 6$ was returned to its original potential. $C$, Extracellular junction potentials in E4 recorded with a suction electrode implanted on the muscle. Spikes in C6 were followed, at fixed latency, by extracellular junction potentials in $\mathrm{E} 4$, which facilitated. $D$, Firing $C 2$ excited $\mathrm{C} 6$, which induced extracellular junction potentials in muscle E4. Biphasic appearance of the junction potentials is due to the relatively short time constant of the recording apparatus. IPSPs in motor neuron C6 were not due to $\mathrm{C} 2$, but to spontaneous neural activity.
C4 or C5, although, based on their size and position, both cells appear to be present on the map. It is possible that these connections are indicated in smaller cells on the map. It is also possible that the connections may not have been noted because they are evident only if $\mathrm{C} 2$ is fired at relatively high frequency. Also, in the case of neuron $\mathrm{C} 4$, little or no synaptic potential is recorded if the cell is at a relatively hyperpolarized potential.

The most recent report of McCaman and Weinreich (1985) has a map of the $E$ cluster and indicates a large neuron, labeled "E," that appears to be $C 5$. In addition, it appears that our $C 9$ and their IE and II neurons may be our C6 and C7, respectively.

Identified cells $C 6$ and $C 7$ are presumptive motor neurons whose activity can be modulated by C2. Two of the followers of $\mathrm{C} 2$ that we have identified, $\mathrm{C} 6$ and $\mathrm{C} 7$, produce muscle contractions. Firing of neuron $\mathrm{C} 6$ caused a short-latency contraction of extrinsic buccal muscle E4 (Figs. $1 B, 7$ ). The contraction could also be produced when the ganglion and muscle were bathed in a high divalent cation solution (Fig. $7 A$ ). Further evidence that C6 is a motor neuron was obtained from extracellular recordings of the activity of E4, using a suction clcctrode. When C6 was fired, E4 received one-for-one extracellular junction potentials, which showed facilitation (Figs. $7 C, 8 A$ ) and post-tetanic potentiation (Fig. $8 B$ ). We have indirect evidence that $\mathrm{C} 6$ may also innervate muscle E5. We observed that, in the reduced preparation, firing $\mathrm{C} 6$ caused both E4 and E5 to contract, and that the contraction in E5 after C6 was fired persisted after E4 was cut. In addition, contractions of E5 after C6 was fired persisted when the ganglion and the muscles were bathed in a high divalent cation solution.

Firing of neuron $\mathrm{C} 7$ produced reliable, short-latency contractions of a large, greenish, body-wall muscle, BW1 (Fig. $1 B$; see legend for description of body-wall muscles; see also Fig. $6 \mathrm{C}$ ), and contractions could still be elicited when the ganglion and muscle were bathed in a high divalent cation solution.

Neuron C2 was able to modulate muscle contractions by means of its connections to the presumptive motor neurons $\mathrm{C} 6$ and $\mathrm{C} 7$. If $\mathrm{C} 2$ was fired strongly, it inhibited IPSPs in C6 and produced a slow depolarization (Fig. $7 B$ ), which resulted in a train of action potentials in neuron $\mathrm{C} 6$ and a concomitant contraction of muscle E4 (Fig. $7 B_{1}$ ). If C6 was hyperpolarized, however, action potentials could not be induced in it by $\mathrm{C} 2$, which has no direct effect on the muscle (Fig. $7 B_{2}$ ). Once C6 was returned 
A

Figure 8. Extrajunctional potentials in $\mathrm{E} 4$ induced by firing $\mathrm{C} 6$ show facilitation and post-tetanic potentiation. $A$, Facilitation of the extracellular junction potentials. $\mathrm{C} 6$ was fired at different rates by intracellular depolarizing current pulses for $500 \mathrm{msec}$. Extracellular junction potentials in E4 were recorded with a suction electrode implanted on the muscle. $B$, Post-tetanic potentiation of the extraccllular potential. Same preparation as $A . \mathrm{C} 6$ was fired at $10 \mathrm{pps}$ for 500 msec by intracellular depolarizing current pulses. After a delay of 125 or $250 \mathrm{msec}$, it was fired again. The potentiation rapidly decreased, and was almost gone when the interval between the train and the final spike was increased to $500 \mathrm{msec}$.

$$
5 \text { PPS }
$$

E4

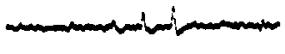

C6

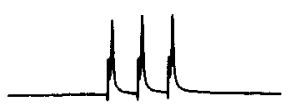

15 PPS

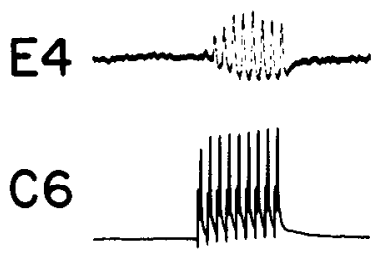

\section{PPS}
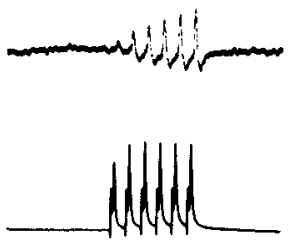

20 PPS

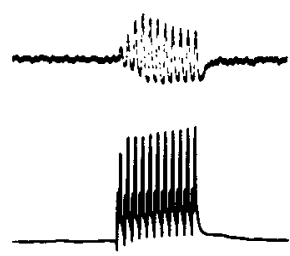

B

\section{PPS $/ 125 \mathrm{~ms}$}

E4

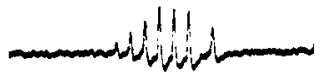

C6

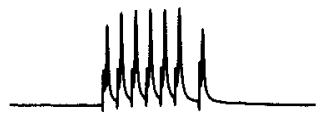

\section{IOPPS / $250 \mathrm{~ms}$}

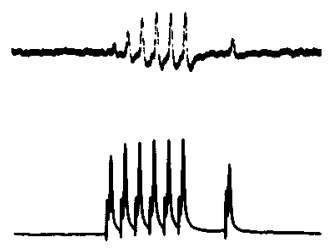

to a depolarized potential, $\mathrm{C} 2$ could again exert its effect on muscle E4 (Fig. $7 B_{3}$ ). These results were supported by recording extracellular potentials of muscle E4. Firing neuron $\mathrm{C} 2$ induced a burst of action potentials in C6, which induced a facilitating burst of extracellular junction potentials in muscle E4 (Fig. 7D). When $\mathrm{C} 6$ was hyperpolarized, however, firing $\mathrm{C} 2$ produced no potentials in E4.

\section{$\underset{400 \mathrm{msec}}{\operatorname{lomv}}$}

If a muscle contraction was elicited in body-wall muscle BW1 by firing neuron $\mathrm{C} 7$, the firing of neuron $\mathrm{C} 2$ was also able to inhibit the firing of neuron $\mathrm{C} 7$, thereby indirectly reducing the contraction that $\mathrm{C} 7$ induced in body-wall muscle BWI (Fig. 6C).

Neuron $\mathrm{C4}$, an excitatory follower of neuron $\mathrm{C2}$, inhibits the motor effects of $\mathrm{C} 6$ and $\mathrm{C} 7$ peripherally. Neither $\mathrm{C} 4$ nor $\mathrm{C5}$
A

Figure 9. Neuron C4 inhibits contractions of extrinsic buccal muscle $\mathrm{E} 4$, which are induced by firing motor neuron $\mathrm{C} 6 . A, \mathrm{C} 6$ was fired at a rate of $20 \mathrm{~Hz}$ by individual depolarizing current pulses for $2 \mathrm{sec}$, followed by a $20 \mathrm{sec}$ rest period. Tension in muscle $\mathrm{E} 4$ was monitored by a strain gauge. Neuron $C 4$ was fired with a steady depolarizing current at about $20 \mathrm{~Hz}$ for $20 \mathrm{sec}$. The ganglion and muscle were bathed in ASW. Firing C4 blocked the contraction of $\mathrm{E} 4$ due to firing C6. $B$, The ganglion and muscle were bathed in a $6 \times \mathrm{Ca}^{2+}, 3 \times \mathrm{Mg}^{2+}$ solution. Firing $\mathrm{C} 4$ still blocked the contraction of $\mathrm{E} 4$ due to firing $\mathrm{C} 6$.

B

ASW

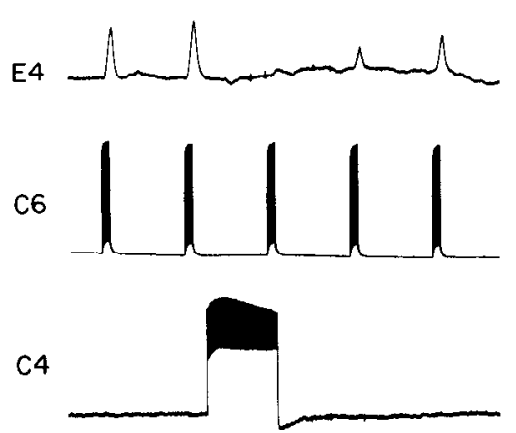

$6 \times \mathrm{Ca}^{2+}, 3 \times \mathrm{Mg}^{2+}$
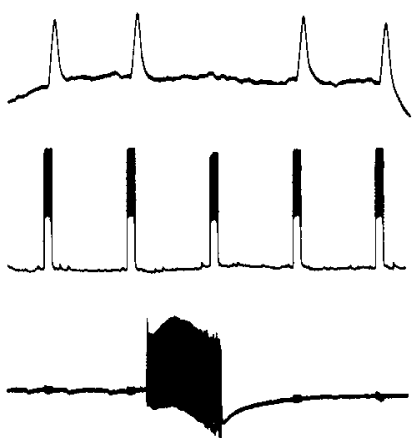

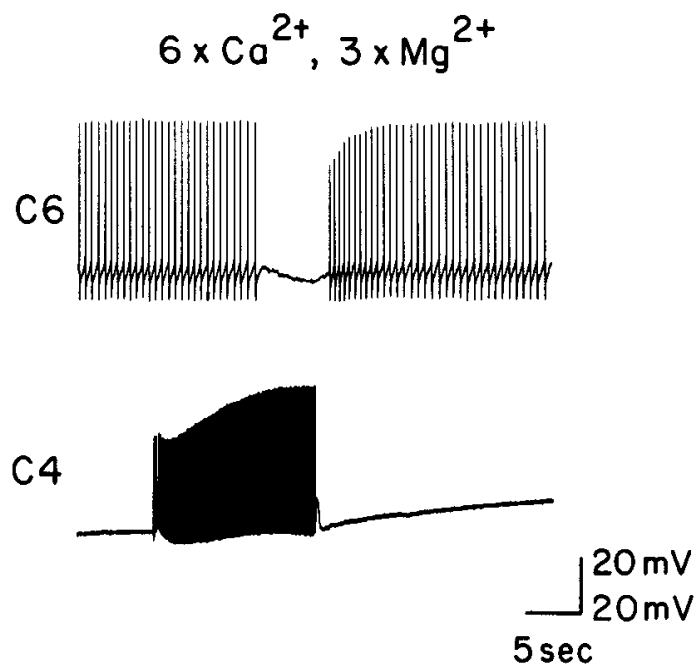

Figure 10. High-frequency firing of neuron $\mathrm{C} 4$ can inhibit motor neuron $\mathrm{C} 6$ centrally. The ganglion was bathed in a $6 \times \mathrm{Ca}^{2+}, 3 \times \mathrm{Mg}^{2+}$ solution. $\mathrm{C} 4$ was fired by a steady depolarizing current. The inhibition in $\mathrm{C} 6$ occurred after a long and variable delay.

A

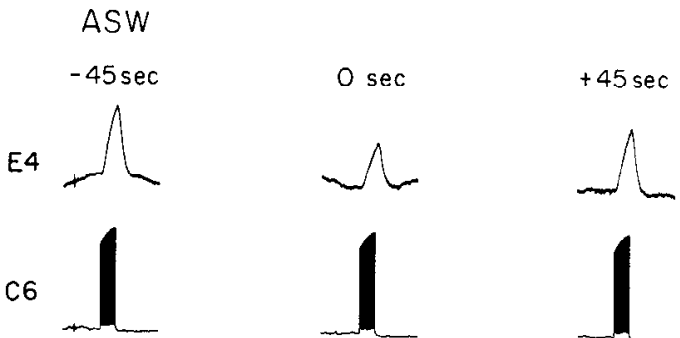

C4

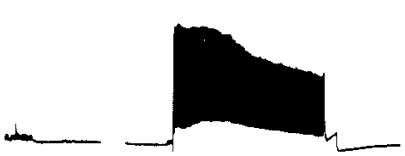

B

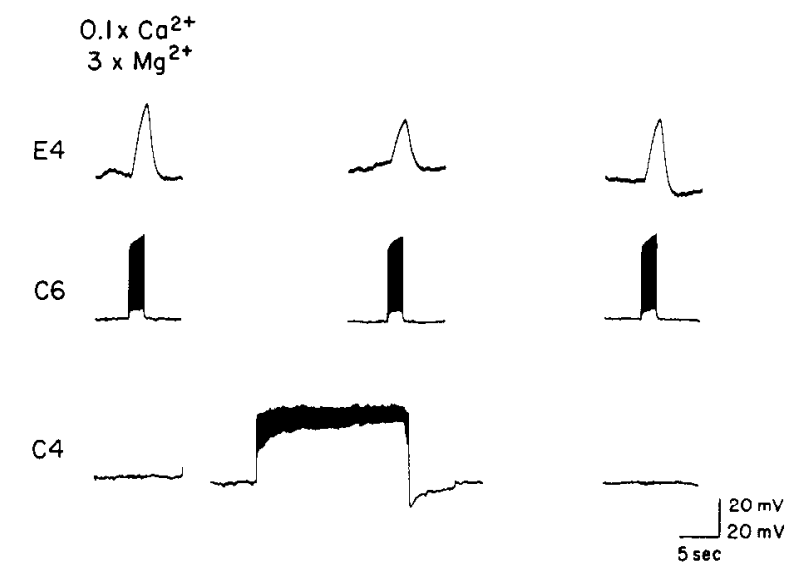

Figure 11. Neuron $\mathrm{C} 4$ acts peripherally to inhibit the contraction of extrinsic buccal muscle $\mathrm{E} 4$ induced by firing motor neuron $\mathrm{C} 6 . \mathrm{A}, \mathrm{C} 6$ was fired at a rate of $20 \mathrm{~Hz}$ by individual depolarizing current pulses for $2 \mathrm{sec}$, followed by a $20 \mathrm{sec}$ rest period. Tension in muscle E4 was monitored by a strain gauge. The cerebral ganglion was isolated from the muscles it innervates by a small Sylgard well whose bottom was coated with Vaseline. C4 was fired with a steady depolarizing current at about $20 \mathrm{~Hz}$ for $20 \mathrm{sec}$. Both the ganglion and the muscle were bathed in ASW. Firing C4 reduced the contraction of muscle E4 due to firing motor neuron C6. $B$. Same preparation as in $A$. The ganglion was now bathed in a $0.1 \times \mathrm{Ca}^{2+}, 3 \times \mathrm{Mg}^{2+}$ solution, which blocks chemical synaptic transmission. The muscle was bathed in ASW. Firing C4 still reduced the contraction of muscle $\mathrm{E} 4$ due to firing motor neuron $\mathrm{C} 6$, even though synaptic transmission in the CNS had been blocked.
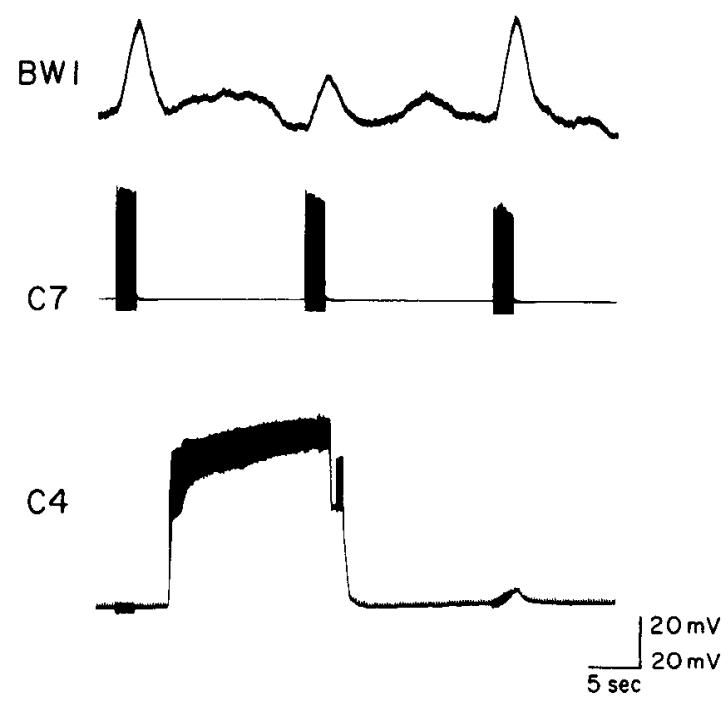

Figure 12. Neuron C4 inhibits contractions of body-wall muscle BW1 induced by firing motor neuron $\mathrm{C} 7 . \mathrm{C} 7$ was fired at a rate of $30 \mathrm{~Hz}$ by individual depolarizing current pulses for $2 \mathrm{sec}$, followed by a $20 \mathrm{sec}$ rest period. Tension in muscle BW1 was monitored by a strain gauge. C4 was fired with a steady depolarizing current at about $20 \mathrm{~Hz}$ for 20 sec.

evoked muscle contractions when fired. Our previous work (Weiss et al., 1978) showed that the MCC, while having no direct motor effect itself, could enhance the motor effect of other cells, and Jahan-Parwar and Fredman (1983) have reported that some $\mathrm{E}$ cluster neurons could modulate the motor effects of other E cluster neurons. We therefore caused the interaction of the firing of $\mathrm{C} 4$ and $\mathrm{C} 5$ with the firing of neuron $\mathrm{C} 6$, which

\section{C2 SYSTEM}

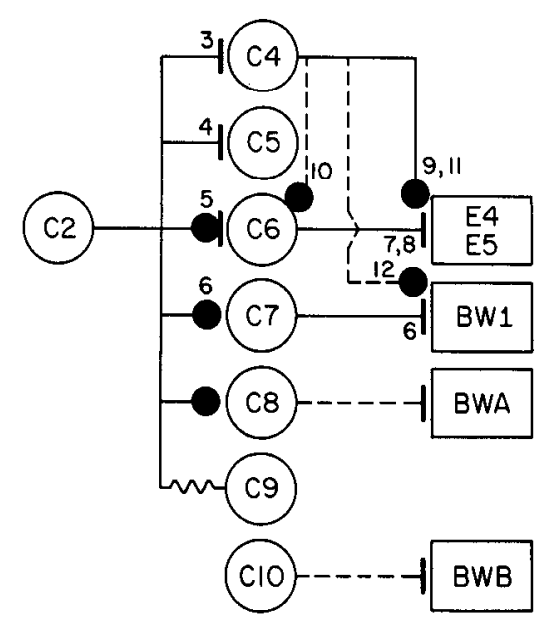

Figure 13. Summary diagram of $\mathrm{C} 2$ and its synaptic followers. This diagram summarizes the data presented in the text and in Figures 112. Excitatory synapses are represented by a line, inhibitory synapses are represented by a circle, and electrical synapses are represented by a resistor symbol. Solid lines represent monosynaptic connections, while dashed lines represent connections that may be monosynaptic or polysynaptic. The numbers labeling individual synapses correspond to the numbers of the individual figures that contain data describing that synapse. Unlabeled synapses were identified during a preliminary survey of $\mathrm{C} 2$ and its synaptic followers, but were not studied in any detail. $E 4$, $E 5$, Extrinsic muscles (see Fig. 1);BWl, body-wall muscle 1 (see Fig. 1); $B W A$, body-wall muscle near the ventral base of the buccal mass; $B W B$, body-wall muscle near the insertion of extrinsic muscle $\mathrm{E} 3$. 
Figure 14. Neuron $\mathrm{C} 2$ and its identified followers, $\mathrm{C} 6$ and $\mathrm{C} 4$, receive synchronous bursts of synaptic input during feeding behavior in the isolated head preparation, and during feeding motor programs in isolated ganglia. $A$, The top trace is a record of the movements of the buccal mass measured by changes in the flow resistance of the buccal artery, as previously described(Weissetal., 1986a). Up arrows indicate the peak of strong forward rotation of the buccal mass; down arrows indicate the peak of strong backward rotation of the buccal mass. Since the direction of movement of the buccal mass was monitored visually, not every movement is indicated. Feeding movements were induced by applying seaweed to the lips of the preparation. Note that when C4 is most powerfully excited, which occurs before the peak of the forward movement of the buccal mass, $\mathrm{C} 2$ often receives inhibition. $B$, Activity in $C 2$ and its follower cells in a preparation consisting of the isolated buccal and cerebral ganglia. The esophageal nerve was stimulated at a rate of $2 \mathrm{~Hz}$, and induced a rhythmic "feeding motor program." $\mathrm{C} 4$ and C5 are identified excitatory followers of $\mathrm{C} 2$; $\mathrm{C} 6$ is a joint inhibitory-excitatory follower of $\mathrm{C} 2$. Note that $\mathrm{C} 2$ and $\mathrm{C} 6$ are inhibited by the synaptic inputs, while $\mathrm{C} 4$ and $\mathrm{C} 5$ are excited. $C$, Expanded records of data in $B_{1-3}$. Note that inputs to all the cells appear to be one-for-one.
A

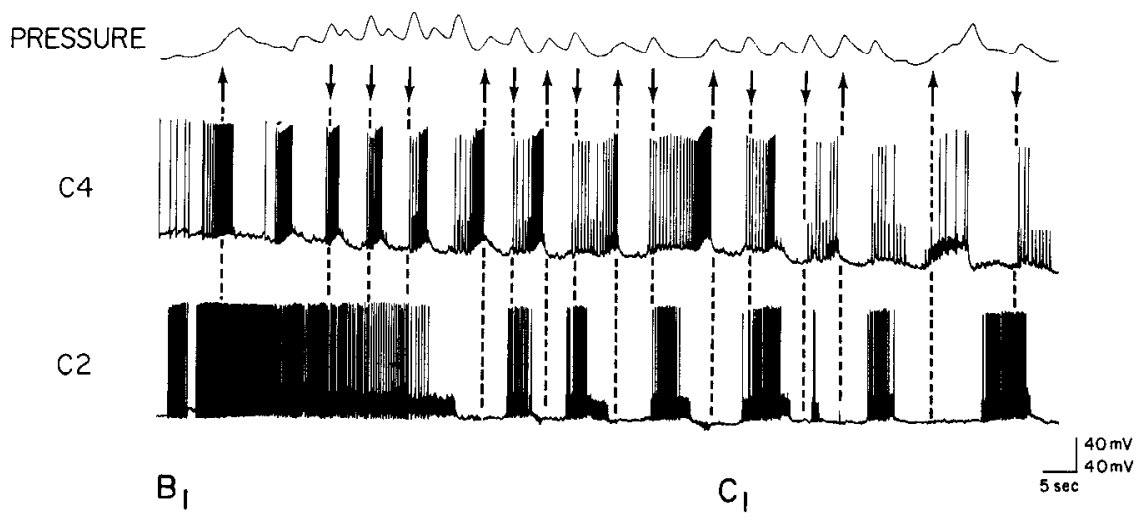

C2
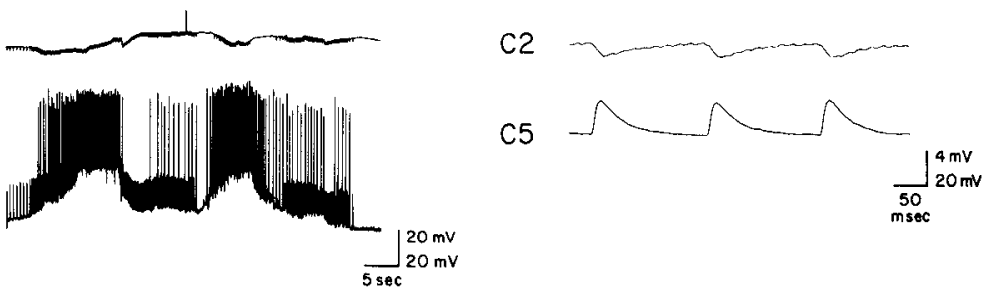

$\mathrm{B}_{2}$

$\mathrm{C} 2$

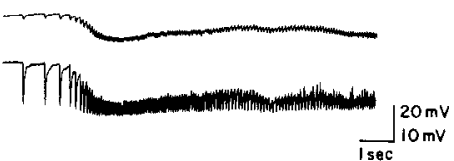

C6

$\mathrm{B}_{3}$

C6

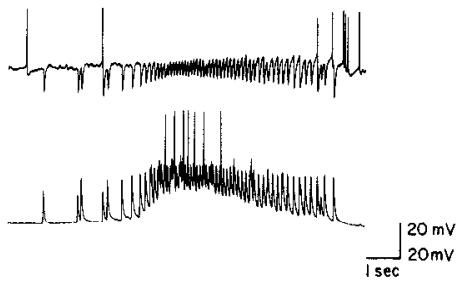

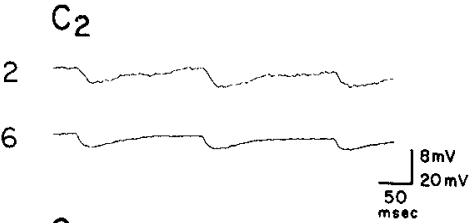

$\mathrm{C}_{3}$

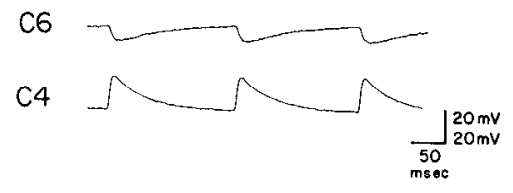

produces muscle contractions. $\mathrm{C} 5$ appeared to have no effect on the muscle contractions caused by firing $\mathrm{C} 6$ or $\mathrm{C} 7$. We found, however, that firing of the excitatory follower $\mathrm{C} 4$ inhibited muscle contractions evoked by a train of spikes in C6 (Fig. 9A). The train of spikes in $\mathrm{C} 6$ was evoked by using brief depolarizing pulses, so that the number and frequency of spikes could be controlled. Under these conditions, firing $\mathrm{C} 4$ produced a 50 $100 \%$ reduction of the magnitude of the contractions of muscle E4. The inhibitory effects of $\mathrm{C} 4$ outlasted the stimulation by $30-40 \mathrm{sec}$. The ability of $\mathrm{C} 4$ to reduce the contraction of the muscle persisted when the ganglion and muscle were bathed in a solution of high divalent cations (Fig. 9B). We found, however,
Figure 15. Neurons C4 and C5 receive synchronous bursts of inputs during feeding-like behavior in the isolated head preparation. Activity of $\mathrm{C} 4$ and $\mathrm{C5}$ was recorded simultaneously from an isolated head preparation during feeding-like behavior. Vertical lines have been drawn at the termination of each burst of $\mathrm{C} 4$ to indicate the synchrony of the bursts of synaptic input and the fixed relationship to buccal movements (monitored by measuring arterial pressure).

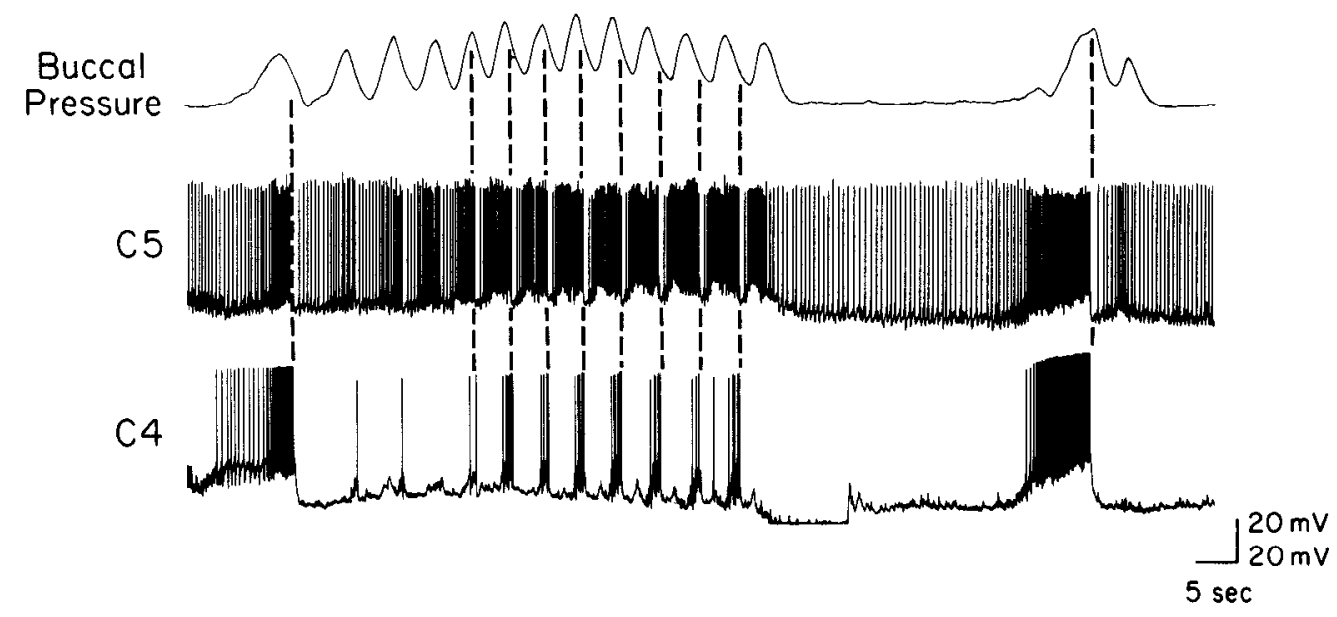


A

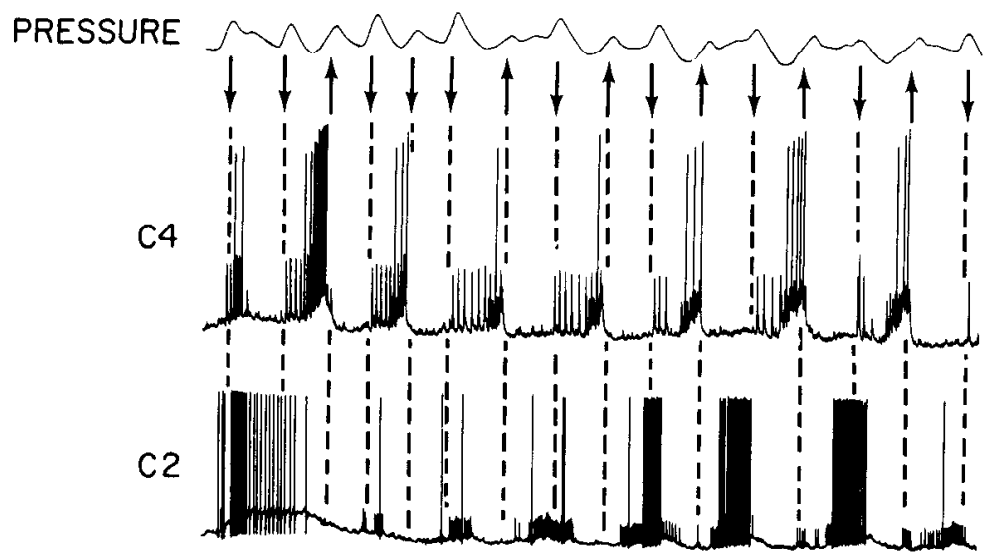

B

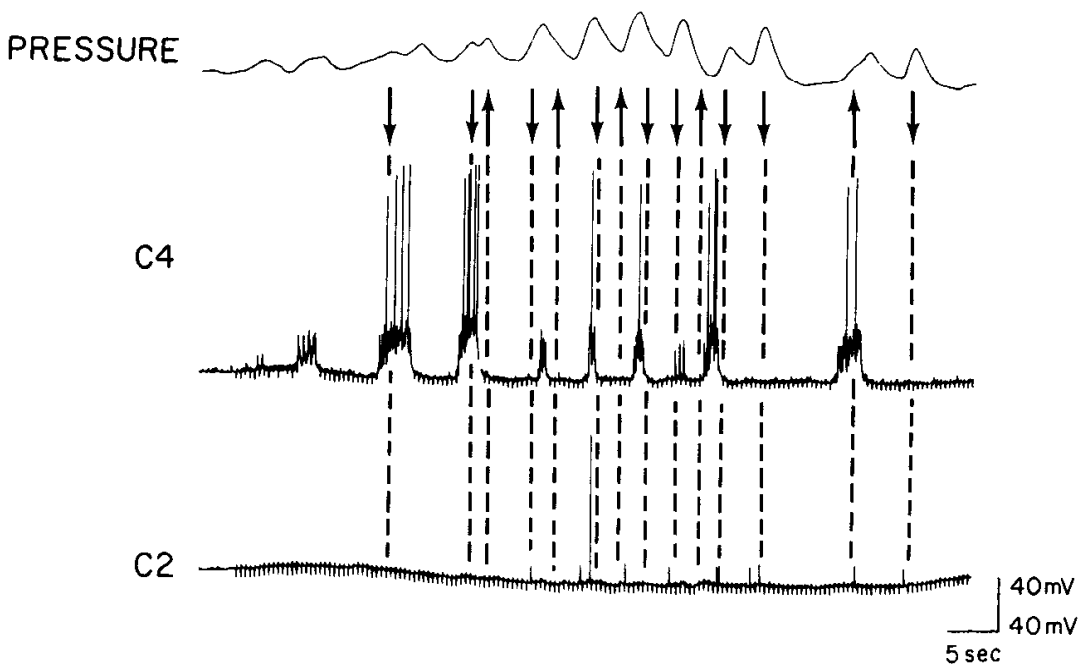

Figure 16. Comparison of inputs to neurons $\mathrm{C} 2$ and $\mathrm{C} 4$ during swallowing-like and rejection-like behavior in an isolated head preparation. $A$, Feeding movements were induced by applying a seaweed strip to the lips of the preparation (compare Fig. 14A). The top trace is a record of movements of the buccal mass (see Fig. 14A for details) as the seaweed strip moved into the buccal cavity. $B$, Same preparation as in $A$. Rhythmic movements were induced by stimulating the esophageal nerve with a hook electrode at a rate of $2 \mathrm{~Hz}$. During stimulation (shock artifacts indicated by short vertical lines) the buccal mass exhibited rhythmic movements (buccal pressure trace, top). The seaweed strip moved out of the buccal cavity, suggesting that the movements represent egestion.

that if $\mathrm{C} 4$ was fired at a high rate ( $>20$ PPS) by individual depolarizing pulses in ASW, or by a steady depolarizing current in a high divalent cation solution, it was capable of inducing a slow IPSP in C6 (Fig. 10). This IPSP was voltage-dependent and could be eliminated by hyperpolarizing C6. Although the IPSP could be induced in a solution of high divalent cations, it is probably polysynaptic, since it has a long and quite variable latency. To establish that $\mathrm{C} 4$ could exert its effects by acting in the periphery even if its central actions were blocked, we isolated, using a small well, the cerebral ganglion from the muscles it innervates. When both the ganglion and muscles were bathed in ASW, C4 could inhibit the contractions of muscle E4 induced by firing neuron $\mathrm{C} 6$ (Fig. $11 \mathrm{~A}$ ). When the ganglion was bathed in a solution that blocked chemical synaptic transmission $\left(0.1 \times \mathrm{Ca}^{2+}, 3 \times \mathrm{Mg}^{2+}\right)$ while the muscles were bathed in ASW, C4 could still inhibit contractions of muscle E4 (Fig. 11B). These results indicate that $\mathrm{C} 4$ probably acts at the periphery, either presynaptically on terminals of $\mathrm{C} 6$, or directly on the muscle. The central inhibitory action of $\mathrm{C} 4$ on $\mathrm{C} 6$ may represent an effect independent of and parallel to the peripheral action of $\mathrm{C} 4$.

We found that, in addition to reducing the contraction of extrinsic muscles of the buccal mass, $\mathrm{C} 4$ was able to reduce the size of the contraction of body-wall muscle BW1. Contraction was elicited by firing the putative motor neuron $\mathrm{C} 7$ with individual depolarizing pulses (Fig. 12). A long train of spikes in $\mathrm{C} 4$ resulted in a reduction in these contractions (Fig. 12).

Figure 13 summarizes the synaptic connections of the cells we have described in this paper.

\section{$C 2$ and its followers $(C 4, C 5, C 6$, and $C 7)$ are activated by feeding motor programs of buccal origin}

In order to determine the role of the follower cells of $\mathrm{C} 2$ in feeding, we recorded the activity of a number of these cells during feeding behavior in the isolated head (semi-intact) preparation or during rhythmic activity in the simplified preparation of the isolated cerebral and buccal ganglia.

In 3 isolated head preparations, we observed that, during the initial response to food, both $\mathrm{C} 2$ and $\mathrm{C} 4$ showed a prolonged burst of activity. During phasic, feeding-like behavior, the highfrequency burst of inputs to $\mathrm{C} 4$ was usually associated with inhibition of $\mathrm{C} 2$ and cessation of its spike activity (Fig. 14A). We also recorded from $\mathrm{C} 4$ together with $\mathrm{C5}$, and observed that they received simultaneous excitation in phase with feeding movements (Fig. 15). For convenience, improved accessibility, and stability, we also studied the activity of $\mathrm{C} 2$ and its follower cells in the simplified preparation (isolated cerebral and buccal 
C7

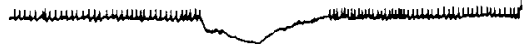

C4
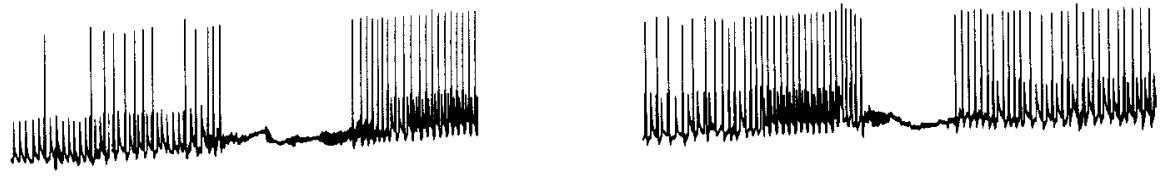

$20 \mathrm{mV}$
$20 \mathrm{mV}$

Figure 17. Neuron C7 appears to receive inhibitory synaptic input during "feeding" motor programs. The esophageal nerve was stimulated while the electrical activity of identified cells $\mathrm{C} 4$ and $\mathrm{C} 7$ was recorded intracellularly. Though the exact phase relation of the inhibitory input is not fixed in the 2 cells, inhibition in one cell was repeatedly associated with inhibition in the other.

A

PRESSURE

RC4

LC4

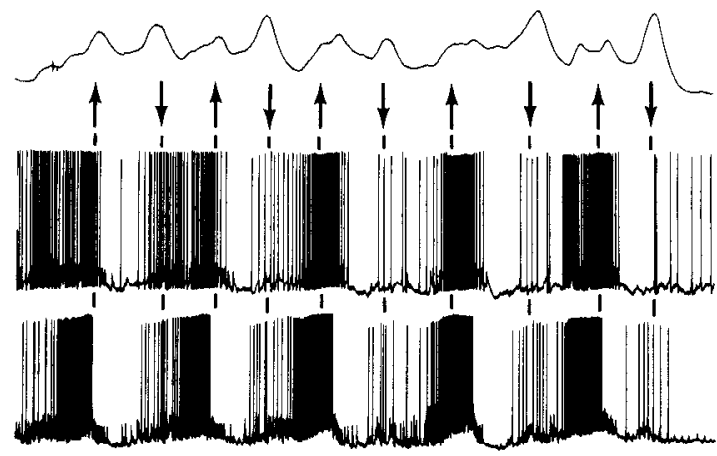

B

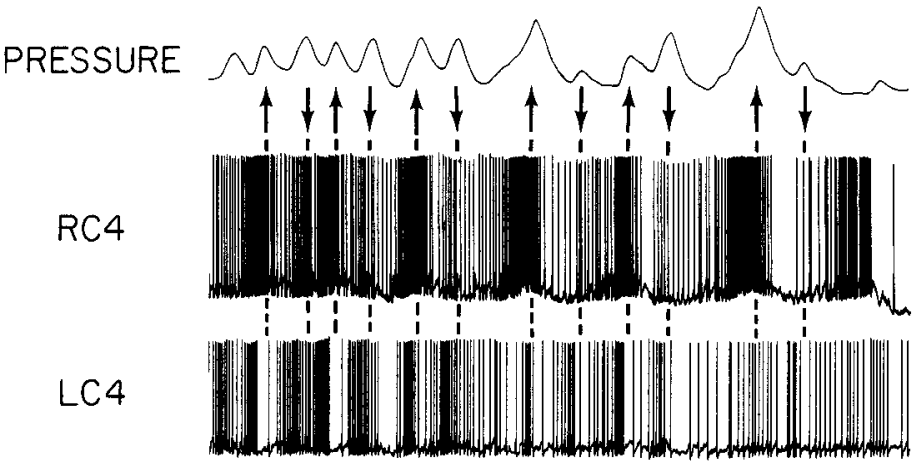

Figure 18. Inputs to identified buccal cell $\mathrm{C} 4$ are of buccal origin and appear to be primarily unilateral. $A$, Activity of neurons $\mathrm{C} 4$ in the right and left $\mathrm{E}$ cluster ( $R C 4$ and $L C 4$, respectively) was simultaneously recorded in the isolated head preparation (see Fig. 14A for description). Feeding movements werc induced by applying seaweed to the lips of the preparation. Note simultaneous bursts of synaptic input to both cells. $B$, Activity in RC4 and LC4 during feeding movements, when the left cerebralbuccal connective was cut. In $B_{1}$ the neurons were at their resting potential. In $B$, the neurons were hyperpolarized in order to better reveal the underlying synaptic potentials.

$\mathrm{B}_{2}$

PRESSURE

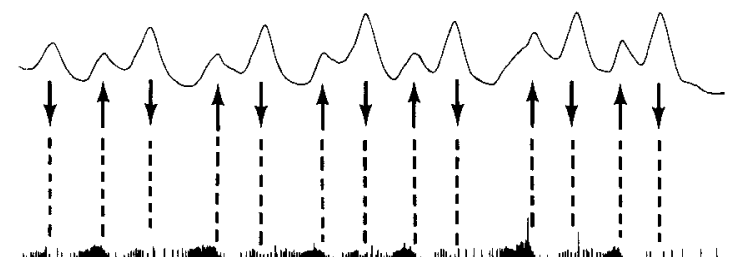

RC4

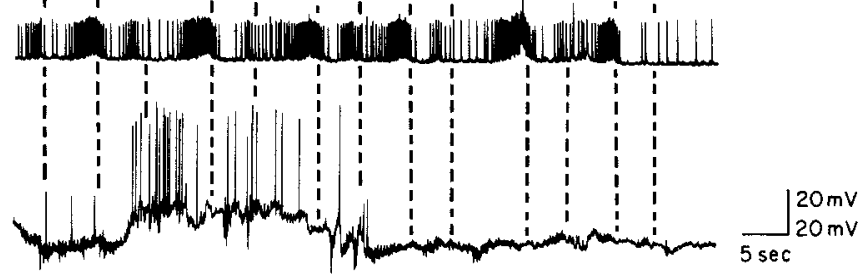


A (signal)

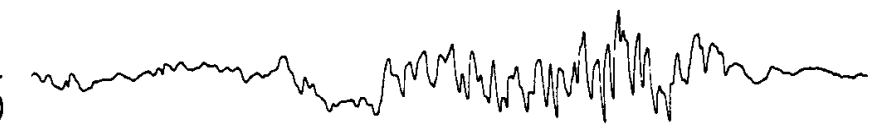

E4

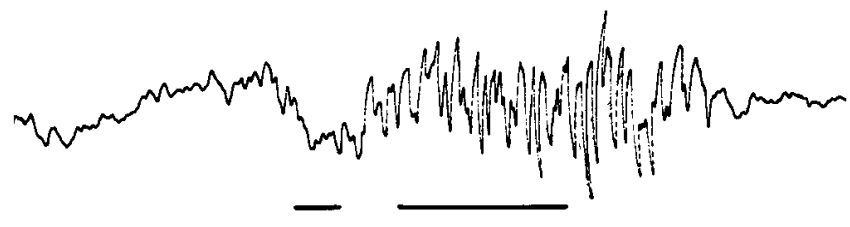

Out

$\ln$

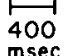

B

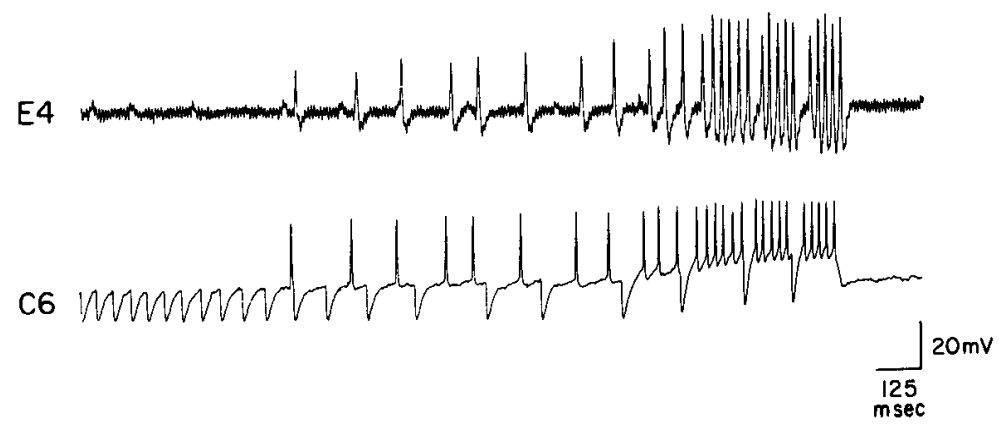

Figure 19. Suction electrodes record field potentials and local muscle extrajunctional potentials. $A$, Recordings from 2 electrodes implanted on muscle E4. "Signal" lead was a form of suction electrode consisting of a silastic tube into which the muscle was drawn. The tube was sealed at the cut end of the muscle, and snugly tied at the other end. The "reference" lead was tied to the outside of the tube, and was thus exposed to the hemolymph of the body cavity. Both leads were referred to an clectrode in the bath during this recording. The record was obtained as the animal swallowed a $0.5 \times 5 \mathrm{~cm}$ strip of seaweed. Bars below the record indicate the movement of the seaweed strip, as determined visually. $B$, Recording from electrode implanted on muscle E4, referenced to an electrode in the bath. The preparation, which had fed normally, was reduced, and the motor cell for E4 (C6) was identified. C6 was steadily depolarized during a spontaneous burst of inhibitory synaptic inputs of buccal origin. The bursts of inputs in muscle $\mathrm{E} 4$ as $\mathrm{C} 6$ fired strongly resembled those seen in the intact, feeding animal. ganglia). Rhythmic "feeding programs" were elicited by tonic stimulation of the esophageal nerve. We found that stimulating the esophageal nerve also induced synchronous bursts of excitatory synaptic input to neurons $\mathrm{C} 4$ and C5.

To obtain some insight into the nature of the motor program elicited by esophageal stimulation in the simplified preparation, we stimulated the esophageal nerve in the isolated head preparation, in which feeding behavior could be observed. After determining that the preparation showed normal, rhythmic feeding movements and swallowing of a seaweed strip (Fig. $16 A$ ), we electrically stimulated the esophageal nerve. Stimulation of the esophageal nerve induced what appeared to be a rejection response. These were rhythmic movements of the buccal mass in which strong retractions were followed by weak protractions and the seaweed strip moved outward. During such movements, $\mathrm{C} 4$ received phasic bursts of excitatory input (Fig. $16 B$ ), while $\mathrm{C} 2$ was inactive (see also Fig. 14, $B, C$ ).

Since $\mathrm{C} 6$ is a much smaller cell than either $\mathrm{C} 4$ or $\mathrm{C} 2$, we have found it very difficult to obtain adequate penetration of it in the isolated head preparation. In studies of 10 isolated head preparations, in which we attempted to examine the activity of C6, we obtained only one penetration in which this neuron was unequivocally identified on the basis of its position, the presence of large IPSPs, and its ability to elicit extracellularly recorded junction potentials in muscle E4. In 2 other preparations, neurons were identified as $\mathrm{C} 6$ on the basis of less complete criteria. These preliminary observations suggested that C6 shows spike activity in association with buccal movements. Firing of neuron $\mathrm{C} 2$ was not very effective in firing $\mathrm{C} 6$, and the major excitatory input to $\mathrm{C} 6$ was not provided by the firing of $\mathrm{C} 2$.

To provide further evidence that the activity of $\mathrm{C} 6$ is related to some aspect of feeding, we studied its activity during "rhythmic motor programs" in the simplified preparation. Stimulation of the esophageal nerve induced powerful rhythmic bursts of IPSPs in C6, which occurred on a one-to-one basis with IPSPs in C2 and EPSPs in $\mathrm{C} 4$ and $\mathrm{C} 5$ (Fig. 14, $B, C$ ). In the same type of preparation, we recorded from the body-wall motor neuron $\mathrm{C} 7$. C7 received inhibitory synaptic input at about the same time that $\mathrm{C} 4$ ccased to receive synaptic inputs, but the inhibition in the 2 cells was not precisely synchronous (Fig. 17).

Inputs to followers of $\mathrm{C} 2$ during feeding motor programs come from the buccal ganglion. Our data suggested that $\mathrm{C} 2$ and its followers receive synaptic inputs that might shape their pattern of activity during feeding behavior. In addition, studies by Jahan-Parwar and Fredman (1983) on isolated buccal and cerebral ganglia suggest that such input to E cluster cells may derive from the buccal ganglion. To confirm this and to determine whether input occurs during feeding, we impaled the right and left $\mathrm{C4}$ neurons of the $E$ clusters and recorded their activity during feeding behavior evoked by seaweed stimulation of the isolated head. During feeding movements, both cells received simultaneous bursts of synaptic input (Fig. 18A). Following the severance of a cerebral-buccal connective, the excitatory input to the ipsilateral $\mathrm{C} 4$ was no longer synchronous with feeding behavior (Fig. $18 B_{1}$ ). When the left and right $\mathrm{C} 4$ neurons were hyperpolarized, the effect of severing a cerebral-buccal connective was even clearer: Cell $\mathrm{C} 4$ contralateral to the cut connective received bursts of EPSPs during the forward phase of buccal movements, whereas cell $\mathrm{C} 4$ ipsilateral to the cut connective received no inputs linked to the buccal movements (Fig. 18B $B_{2}$ ). The substantial reduction in the coordinated activity of the left and right $E$ clusters strongly suggests that most of the input to the $\mathrm{C} 4$ neurons is due to buccal neurons that provide unilateral input to the cerebral ganglion. Furthermore, these results suggest that there is relatively little interganglionic coordination between the left and right halves of the cerebral ganglion. Such coordination may be imposed on the cerebral ganglion by coordination within the buccal ganglion. 


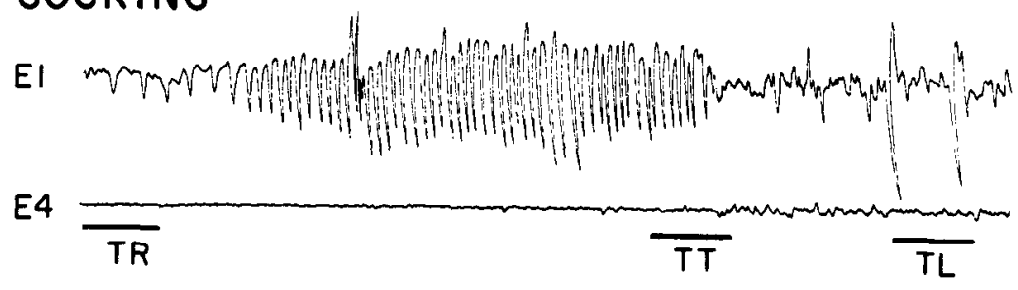

B BITING

Figure 20. Differential activity of extrinsic muscles $\mathrm{E} 1$ and $\mathrm{E} 4$ during feeding behaviors. $A$, Extracellular recordings from suction electrodes implanted on extrinsic muscles E1 and E4 in the intact feeding animal. The record was obtained as the animal was aroused by being touched with seaweed. $T R$, Touch rhinophores; $T T$, touch tentacles; $T L$, touch lips. Gain of top channel is $3 \times$ that of bottom channel. $B$, Same preparation as in $A$. The record was obtained as the animal bit, but did not swallow, a piece of seaweed. Bars below the record indicate the observed behavior of the lips and jaws of the animal. Open, Jaws open as radula protracts; Close, jaws close as radula retracts. $C$, Same preparation as in $A$. The record was obtained as the animal swallowed a $0.5 \times$ $5 \mathrm{~cm}$ strip of seaweed. Bars below the record indicate observations of the movement of the strip into the animal's mouth. $D$, Same preparation as in $A$. Animal was induced to swallow a length of silastic tubing by stimulating its lips with seaweed. After several swallows, the animal began to reject the tube. Bars below the record indicate observations of the movements of the tube out of the animal's mouth.

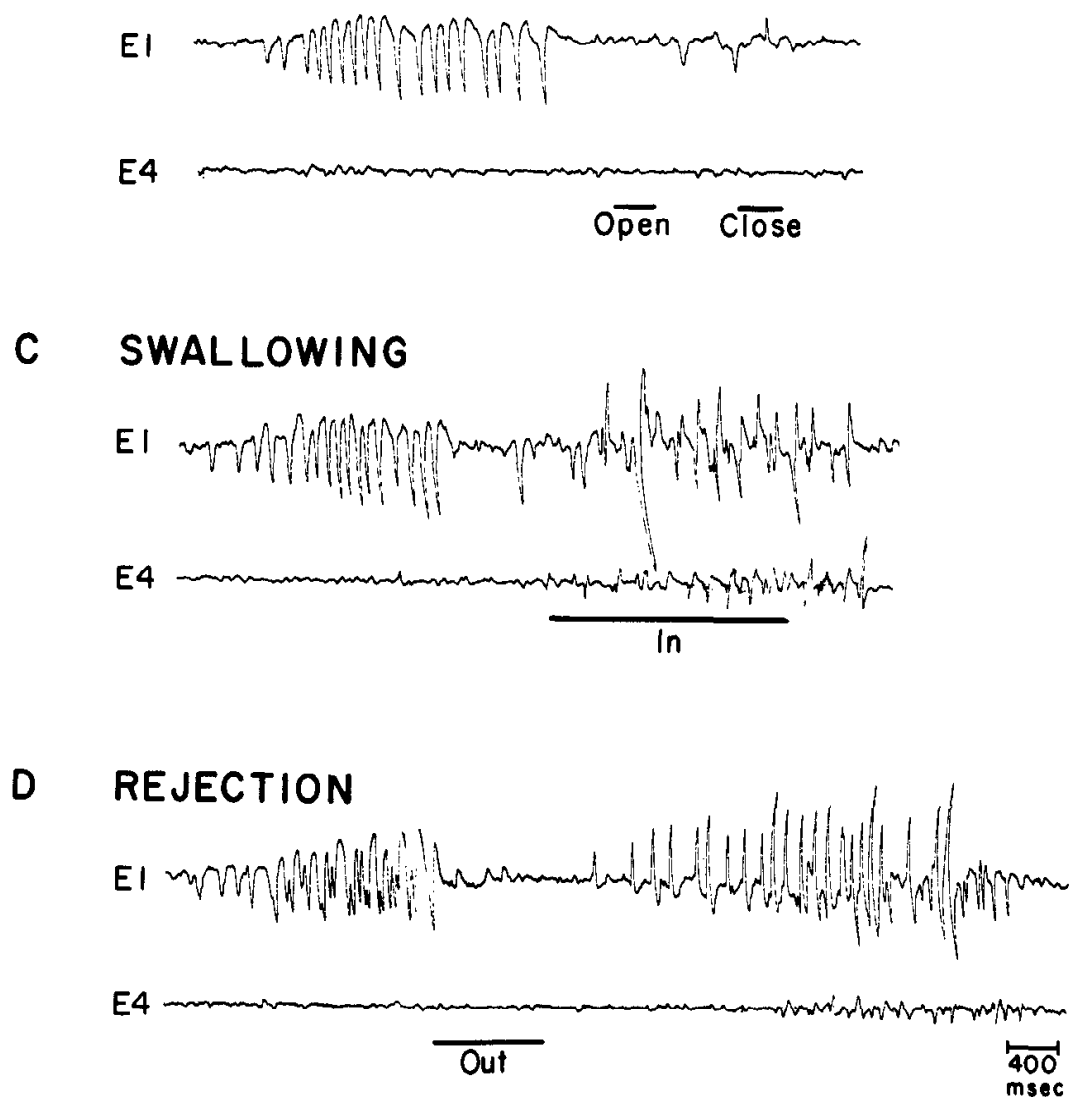

As was discussed previously, when rhythmic buccal activity was evoked by stimulation of the esophageal nerve in isolated ganglia preparations, many of the synaptic potentials evoked in neurons $\mathrm{C} 2, \mathrm{C} 5$, and $\mathrm{C} 6$ were synchronous with those in $\mathrm{C} 4$ (Figs. 14, B, C). This suggests that at least one source of synaptic input to neurons $\mathrm{C} 2, \mathrm{C} 5$, and $\mathrm{C} 6$ is also buccal in origin. Indeed, we have identified several neurons in the buccal ganglion that provide synaptic input to these and other neurons of the E cluster (H. J. Chiel, K. R. Weiss, and I. Kupfermann, unpublished observations).

\section{Muscles modulated by $C 2$ are active during swallowing and may contribute to the efficiency of swallowing}

Anatomy of muscles E4 and E5. In order to clarify the role C2 might play in modulating motor activity during feeding, we studied the gross anatomy of the 2 muscles, E4 and E5, whose motor cell, $\mathrm{C} 6$, is modulated by $\mathrm{C} 2$. These muscles, as well as $\mathrm{E} 1, \mathrm{E} 2, \mathrm{E} 3$, and E6, are termed "extrinsic buccal muscles" since they have one attachment site on the buccal mass, and a second attachment site on a structure external to the buccal mass. The anatomy of the extrinsic muscles has been described previously (Cuvier, 1803; Howells, 1942) and, in the course of our research, there appeared an extensive anatomical and physiological study of this system by Jahan-Parwar and Fredman (1983).

Our studies (see Fig. $1 B$ ) have revealed that muscles E4 and $E 5$ both insert into the anterior dorsal part of the jaw cartilage, which constitutes the most forward upper part of the buccal mass. Both muscles have their origin in the dorsal lateral head tissue. However, they are divided from one another by a thin red muscle, E1, which runs between them at their insertion into the jaw. Muscle E5, which inserts more laterally into the jaws than E4, also inserts more laterally and posteriorly than muscle E4 into the head tissue above the buccal mass, at about the level of the rhinophores. In addition, muscle E4 has several branches, one of which inserts into anterior head tissue. Because of their inscrtion at the far anterior tip of the buccal mass, ncither musclc is well suited to pull the buccal mass forward or back. However, acting in concert, it is possible that they raise the top of the jaw cartilage and thus help to pull the jaws shut. They could also act to stabilize and center the buccal mass during feeding.

The current nomenclature for the extrinsic muscles and relevant neurons in the cerebral ganglion is somewhat confusing. Jahan-Parwar and Fredman (1983) have described six pairs of extrinsic buccal muscles. They name the extrinsic muscles by using the prefix "Ex," followed by a term describing the location 
A

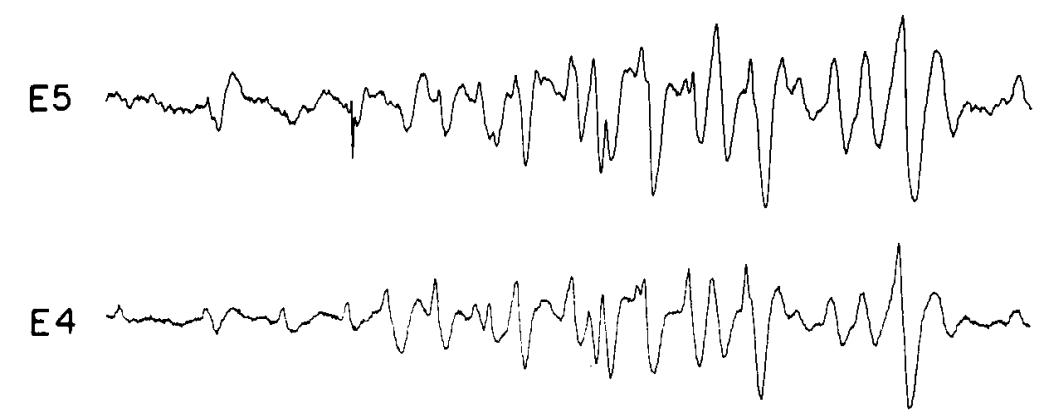

B

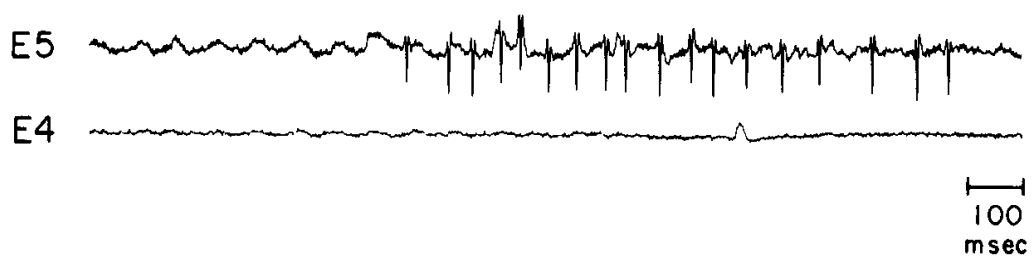

C

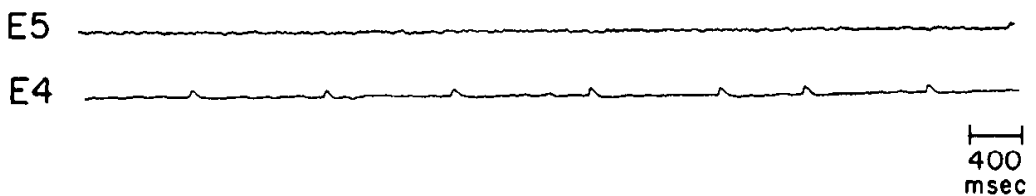

Figure 21. Extracellular suction electrodes implanted on muscles E4 and E5 record both similar and dissimilar potentials in each muscle. $A$, Extracellular recordings from suction electrodes implanted on muscles E4 and $\mathrm{E} 5$ in the intact, feeding animal. The rccord was obtained as the animal swallowed a strip of seaweed. Note that activity recorded in the 2 muscles appears almost completely synchronous. $B$, Same preparation as in $A$. Shortly before a rejection movement, small, fast potentials were recorded by the electrode implanted on muscle E5, while little or no activity was recorded in the electrode on muscle E4. $C$, Same preparation as in $A$. During a quiescent period, small, slower potentials were recorded by the electrode implanted on muscle E4, while little or no activity was rccorded in the electrode implanted on muscle E5. and presumed function of the muscle (e.g., ExVLP-extrinsic ventral lateral protractor). Several other descriptions of the buccal musculature of Aplysia also exist (Cuvier, 1803; Howells, 1942). We have fully confirmed Jahan-Parwar and Fredman's anatomical description of these muscles, but, nevertheless, we have opted to use an extension of the nomenclature of Howells (1942) for several reasons. First, Howells reported the first systematic study of the buccal muscles of Aplysia, and his nomenclature has been used by others (Ram et al., 1984). Second, and more important, we wished to avoid functional terms such as "retractor" or "protractor," since we have found that, for many of these muscles, simple functional terms were not adequate, and the proposed function of a muscle was likely to change as we learned more about it. Thus, for example, we have found that the so-called extrinsic anterior lateral and ventral protractors (ExALP and ExVLP in the nomenclature of Jahan-Parwar and Fredman) show little or no electrical activity during biting responses, even though biting is characterized by a powerful protraction movement (Figs. 22 $A ; 23, A_{1}, B_{1}$; see also Brace and Quicke, 1981, and Peters and Altrup, 1984, for a similar classification problem in other mollusks).

Extracellular recordings from extrinsic muscles $E 4$ and $E 5$. Our results from the reduced preparation indicated that $\mathrm{C} 6$ provided motor inputs to extrinsic buccal muscles and that $\mathrm{C} 7$ provided motor inputs to a body-wall muscle. Recording the activity of these muscles in the intact animal might reflect the activity of $\mathrm{C} 2$ and its followers, and provide a means of assessing the functioning of the system in normal feeding. We therefore implanted suction electrodes on several extrinsic buccal muscles (E4, E5, and E1) and body-wall muscle BW1.

Suction electrodes record field potentials as well as muscle potentials during behavior. Although extracellular recording from molluscan muscle has been used previously to infer muscle activity (e.g., Croll and Davis, 1981; Jacklet and Rine, 1977), we found that the results obtained from extracellular recording can be difficult to interpret because the electrode may record not only local muscle or nerve potentials, but field potentials as well. We will present evidence that both can be recorded by an extracellular electrode, but that one can nevertheless make use of the resulting data to analyze muscle activity.

We first implanted suction electrodes on muscle E4 and found that we could record relatively large potentials, phase-locked to feeding behavior (see section below). Since the buccal muscles of Aplysia consist of a dense meshwork of different muscles in close proximity, potentials recorded from one muscle could consist of local potentials as well as distant field potentials generated by other muscles.

To approach this problem, we implanted 2 electrodes on muscle E4. One lead (the signal lead) recorded potentials from within the silastic tube that contained the muscle. The other lead (the reference lead) was exposed directly to the hemolymph outside the tubing. Differential recordings revealed large potentials during feeding behavior. Both the signal and the reference leads, when referred to an electrode in the bath, independently registered large, synchronous potentials (Fig. 19A), which were of similar but not identical size and phase.

This result could be due to a number of conditions: (1) Muscle E4 generates large field potentials that can be recorded by electrodes that are not in direct contact with the muscle; $(2)$ the potentials recorded in the vicinity of $\mathrm{E} 4$ derive from it as well as from other muscles that generate large field potentials; and (3) under our conditions, E4 does not generate recordable potentials, and the records reflect activity due entirely to distant field potentials. 
A

\section{BITING}

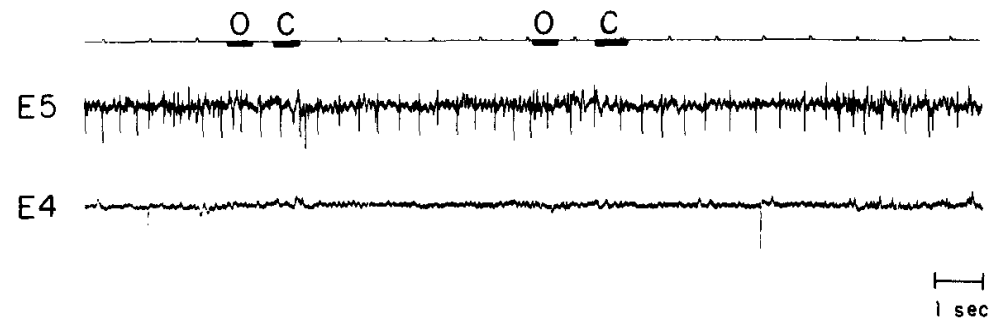

B

SWALLOWING

IN

IN

IN

Figure 22. Extrinsic buccal muscles $\mathrm{E} 4$ and $\mathrm{E} 5$ are activated as a unit during swallowing and rejection movements, and are not significantly activated during biting. They appear to be excited during swallowing and to be inhibited during rejection. $A$, Extracellular recordings from suction electrodes implanted on muscles E4 and E5 in an intact, feeding animal. The record was obtained as the animal attempted to bite, but did not swallow, a piece of seaweed. Bars below the record indicate the observed behavior of the lips and jaws of the animal. $O$. Open (jaws open as radula protracts); $C$, close (jaws close as radula retracts). Small fast potentials seen in the E5 record are identical to those seen in Figure $21 B . B$. Recordings from the same animal as in $A$. The record was obtained as the animal swallowed a strip of seaweed. Bars above the record indicate observations of the movement of the strip into the animal's mouth. $C$, Recordings from the same animal as $A$. The animal was induced to swallow a length of silastic tubing by stimulating its lips with seaweed. After several swallows, the animal began to reject the tube. Bars above the record indicate observations of the movements of the tube out of the animal's mouth.
C REJECTION

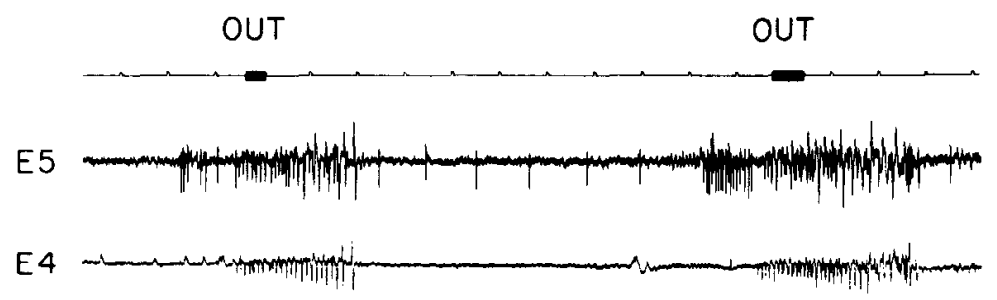

$\stackrel{\longrightarrow}{\mathrm{sec}}$

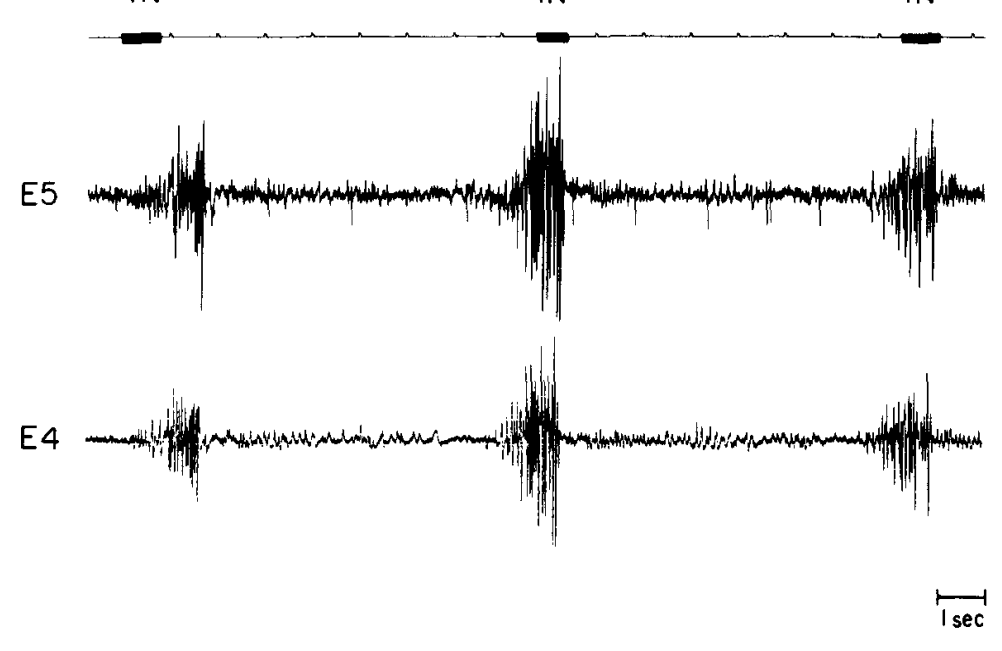

Two lines of evidence appear to rule out the possibility that the extracellular signals are entirely due to distant field potentials. First, in 2 preparations, we recorded potentials from suction electrodes implanted on muscle E4 during feeding behavior, and then dissected the animals (leaving the electrodes intact) so that we could visualize the muscle and the cells of the cerebral ganglion. We were able to identify the motor neuron $\mathrm{C} 6$ for muscle E4, and we found that firing C6 elicited one-for-one potentials in $\mathrm{E} 4$ that were very similar to those observed during behavior in the intact animal (Fig. 19B; see also data in Fig. $7, C, D$, which were recorded from the animal whose behavior is shown in Fig. $23 B$, and the data in Fig. 8, which were recorded from the animal whose behavior is shown in Fig. 23A).

The second indication that extracellularly recorded muscle potentials were not exclusively field potentials was that different extrinsic muscles showed different patterns of activation during feeding behaviors. We implanted electrodes on muscles E4 and E1, which are very different anatomically (see Fig. $1 B$ ). Muscle El showed patterns of activation that were very dissimilar from those of E4 (Fig. 20), again suggesting that the electrodes were recording local muscle potentials. We also implanted electrodes on muscles E4 and E5, which are very similar anatomically (see Fig. $1 B$ ). These experiments showed that, although potentials recorded from the 2 muscles were often synchronous (Fig. 21 $A$ ), sometimes the electrode on E5 recorded potentials that did not appear in the electrode for E4 (Fig. $21 B$ ) and vice versa (Fig. $21 C$ ). These results suggest that, even if the synchronous potentials are field potentials, both electrodes are capable of picking up local muscle potentials unique to E4 or E5. Since muscles E4 or E5 form a large muscle complex at the base of the buccal mass (see Fig. $1 B$ ), their contractions might induce large field potentials in the head of the animal. As a consequence, the synchronous potentials recorded in both muscles might reflect the sum of the local muscle potentials and the ficld potential generated by the muscles.

Activity of muscles E4, E5, and BWI during feeding behavior. We found that muscles E4, E5, and BW1 were activated in essentially identical phases of feeding behavior. The muscles 


\section{BITING}

$A_{1}$

$\mathrm{B}_{\mathrm{I}}$
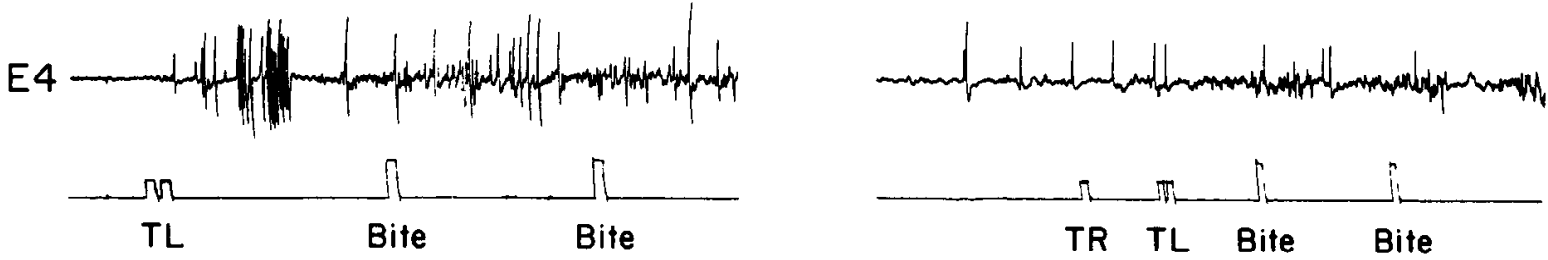

SWALLOWING

$A_{2}$

$\mathrm{B}_{2}$
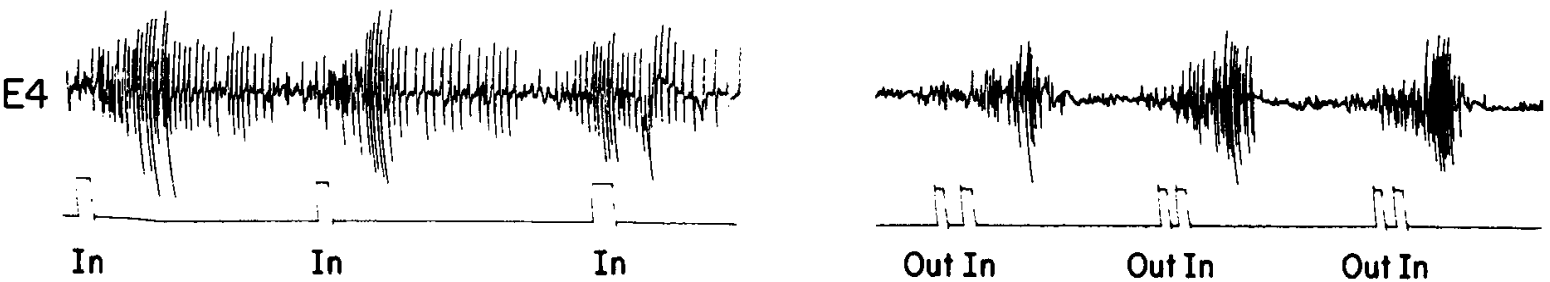

REJECTION

$A_{3}$

$\mathrm{B}_{3}$
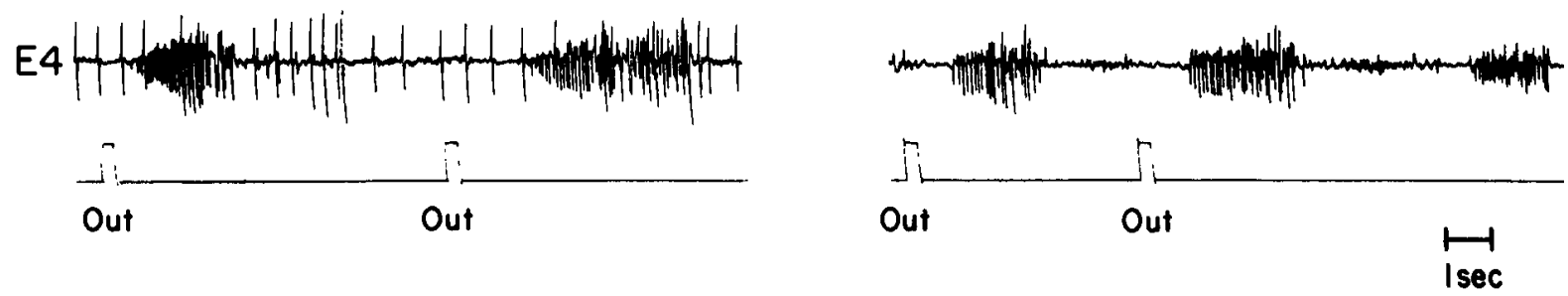

Figure 23. Timing of observed behavior in relation to electrical activity in muscle E4. $A$ and $B$ were obtained from 2 different animals in order to illustrate the degree of variability observed in animals' behavior. $A_{t}$, Extracellular recordings from a suction electrode implanted on muscle E4 in an intact, feeding animal. The record was obtained as the animal attempted to bite, but did not swallow, a piece of seaweed. Stimulus markers below the record indicate the observed behavior of the lips and jaws of the animal. Bite is equivalent to "open" in Figure 22 . Though there was a small burst of activity in the muscle after the animal was touched by seaweed, it did not persist during the animal's bites. $T L$, Touch lips. $A_{2}$, Recordings from the same animal as in $A_{i}$. The record was obtained as the animal swallowed a strip of seaweed. Stimulus markers below the record indicate observations of the movement of the strip into the animal's mouth. Note that $I n$ movements may precede or occur during bursts of activity in muscle E4. $A_{3}$, Recordings from the same animal as in $A_{1}$. The animal was induced to swallow a length of silastic tubing by stimulating its lips with seaweed. After several swallows, the animal began to reject the tube. Stimulus markers below the record indicate observations of the movements of the tube out of the animal's mouth. Note that the Out movements reliably preceded bursts of activity in muscle E4. $B_{1}$, A different animal with a suction electrode implanted on muscle E4. These data were obtained by the method described in $A_{i}$. TR, Touch rhinophores; $T L$, touch lips. Note that muscle E4 was quiescent. $B_{2}$, Same preparation as in $B_{1}$. These data were obtained by the method described in $A_{2}$. In this animal, it was possible to observe a slight outward movement of the seaweed strip shortly before it moved inwards. Note that the Out movements always precede the main burst of activity in the muscle. (Compare with $A_{2}$ and Fig. 22B.) $B_{3}$, Same preparation as in $B_{1}$. These data were obtained by the method described in $A_{3}$. Note that the Out movements reliably preceded bursts of activity in muscle E4 (compare with $A_{3}$ and Fig. $20 C$ ).

were quiescent after the animal was first touched with food. Furthermore, when animals were not permitted to swallow the food, the muscles showed a total lack of any phase-locked activity during vigorous biting responses (Figs. 22A;23, $A_{1}, B_{1}$; data for BW1 not shown). On the other hand, they exhibited large, phase-locked potentials during swallowing and rejection responses. During swallowing, the muscle potentials were primarily positive or biphasic during and after the time food was drawn into the mouth (Figs. $22 B ; 23, A_{2}, B_{2} ; 6 D_{1}$ ). The potentials appeared graded, and resembled those produced by firing of the motor neuron $\mathrm{C} 6$. Therefore, they probably reflect muscle excitatory junction potentials.

During food rejection, E4 and E5 also showed phase-locked electrical activity, but the potentials were often primarily negative in polarity, possibly representing inhibitory potentials (Figs. $\left.22 C ; 23, A_{3}, B_{3}\right)$, although we cannot exclude the possibility that the apparent reversed polarity was due to an excitatory junction potential generated at a site different from the one exhibiting positive polarity. During rejection, muscle BW1 also showed phase-locked bursts of electrical activity (Fig. $6 D_{2}$ ) similar in appearance to those seen during swallowing (Fig. $6 D_{1}$ ). These bursts occurred immediately after outward movement of the rejected material, and thus presumably occurred during retraction movements.

To determine more exactly the timing of feeding behavior in relation to the electrophysiological activity of muscle $\mathrm{E} 4$, we analyzed the mean phase of the inward movement of a seaweed strip in relation to activity in muscle E4 for 195 bursts of activity and/or observed movements in 5 different preparations. We found that bursts of electrical activity and observable movements were associated with one another in $88 \%$ of these cases (i.e., 172 bursts were associated with observable movements). 


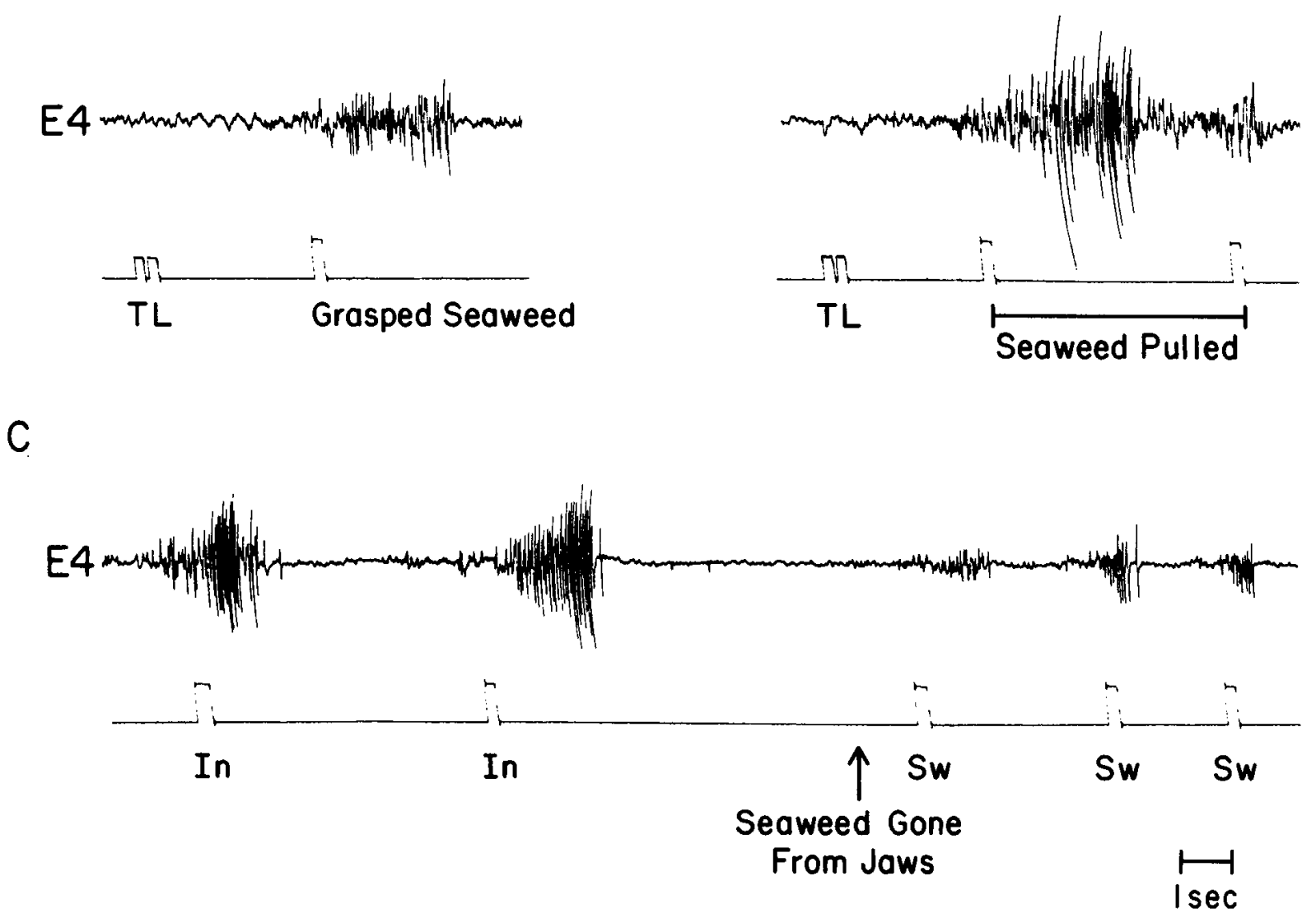

Figure 24. Mechanical and chemical stimulation of the jaws by seaweed appears to enhance the activity of muscle E4. A, Extracellular recordings from a suction electrode implanted on muscle E4 in an intact, feeding animal. The record was obtained by stimulating the animal with seaweed until it grasped the seaweed with its radula. Note the burst of activity in E4 after the animal grasped the seaweed. TL, Touch lips. $B$, Recordings from the same animal as in $A$. The record was obtained by stimulating the animal with seaweed until it grasped the seaweed with its radula. The seaweed was then pulled, preventing the animal from swallowing it. The second stimulus marker indicates when the animal released the seaweed. Note that the activity of E4 increased while the seaweed was pulled and decreased shortly before the animal released the seaweed. $T L$, Touch lips. $C$, Recordings from the same animal as in $A$. The record was obtaincd as the animal swallowed a strip of seaweed. Note that after the seaweed could no longer be seen between the jaws, the activity of muscle E4 markedly decreased. During the first swallowing movement (as indicated by a mouth opening) that occurred after seaweed had gone from the jaws, the seaweed could still be seen in the radula. In, Inward movement of seaweed strip; $S w$, swallow (jaws open slightly, radula can be glimpsed between them).

Analysis of these 172 bursts of activity showed that in $37 \%$ of these cases ( 63 bursts), the inward movement of the strip preceded the electrophysiological activity in the muscle, while in $62 \%$ of these cases (107 bursts), the inward movement occurred during the burst of activity (typical examples from 3 different preparations are shown in Figs. $22 B ; 23, A_{2}, B_{2}$ ). The most probable occurrence of the beginning of the inward movement ranged from $400 \mathrm{msec}$ before the electrophysiological activity to $200 \mathrm{msec}$ after the activity had begun.

We also analyzed the timing of the outward movement of material from the mouth during rejection in relation to activity in muscle E4 (49 bursts of activity and/or observed movements in 5 different preparations), and found that in $51 \%$ of these cases (i.e., 25 bursts), bursts of electrical activity and observable rejection movements were associated with one another. The lower rate of association reflects both the irregular occurrence of rejection movements and their smaller magnitude, which makes them more difficult to observe. Analysis of the 25 bursts showed that in $68 \%$ of these cases (17 bursts), the outward movement preceded the electrophysiological activity in the muscle, while in $32 \%$ of these cases ( 8 bursts), the outward movement occurred early during the activity in the muscle (typical examples from
3 different preparations are shown in Figs. $22 C ; 23, A_{3}, B_{3}$ ). The most probable occurrence of the beginning of the outward movement ranged from 600 to $300 \mathrm{msec}$ before the beginning of the electrophysiological activity.

It should be noted that, during some bouts of swallowing, it was possible to observe a brief outward movement of the seaweed strip before it moved inwards (a typical example is shown in Fig. $23 B_{2}$ ). The phase of this outward movement seems similar to the phase of the outward movement of rejection (compare Fig. $23 B_{3}$ ), although it is not as early and is not associated with prominent negative potentials in E4.

We also explored the effects of varying the size and length of the seaweed strips we fed the animals to see if the intensity of the output of muscle E4 changed. Aside from a change in the rate of movements (Weiss et al., 1986b), relatively little difference was noted in the intensity of the electromyographic response as a function of the width of the strip. However, when we varied the load on the muscle by pulling on the strip, we observed increases in the phasic activity in the muscle (Fig. $24 B$ ). We also observed that if the animal failed to grasp the seaweed, the muscles showed little activity associated with the bite (Fig. $22 A$ ), but that the activity in the muscle significantly 
increased once an animal had succeeded in grasping the seaweed (Fig. 24A). Finally, we observed that, during swallowing, whenever seaweed could no longer be seen between the jaws, and small "swallowing" movements were made (as determined by swelling of the head and small opening movements of the mouth), the activity in the muscle decreased (Fig. 24C).

Activity of extrinsic muscle E1 during feeding. Jahan-Parwar and Fredman (1983), in an earlier study of the extrinsic muscles of the buccal mass, suggested that muscle El (which they designate as the extrinsic dorsal protractor, ExDP) was involved in the protraction of the buccal mass, and they reported that the $E$ cluster of the cerebral ganglion contained a motor neuron for that muscle. In studies in over 25 preparations, we were unable to find any motor cells for this muscle in the $E$ cluster. Our results suggest that $\mathrm{E} 1$ is involved in protraction but, on the basis of electrical recordings from the muscle, it is not clear whether E1 is inhibited or excited during protraction. Specifically, we found that the muscle showed electrical activity shortly after an animal was touched with seaweed (Fig. 20 A), and shortly before the radula protracted through the jaws during biting (Fig. $20 \mathrm{~B}$ ), during the time the animal was cocking the buccal mass and protracting the radula. These potentials, however, were primarily negative-going, which, in muscle E4, appears to represent inhibitory potentials (see previous section). It is possible that, because of the geometrical location of the synaptic currents in $\mathrm{E} 1$, these negative potentials represent excitatory input, but since we have not located motor neurons for muscle El, we cannot resolve this question.

During swallowing (Fig. 20C), El exhibited negative potentials primarily before the seaweed strip moved inward, that is, during the time the animal protracted its radula over the strip prior to the retraction that pulled the strip inward. During the inward movement of the seaweed, at the same time that E4 was exciled, E1 exhibited biphasic electrical activity.

During rejection (Fig. 20D), E1 exhibited a strong burst of negative potentials just before material moved out of the mouth, which corresponds to the time the radula was protracting. It also showed a burst of inputs of opposite polarity during the time the radula retracted, and during the time that $\mathrm{E} 4$ received excitatory input.

Lesions of extrinsic musculature reduce the efficiency of swallowing. In order to determine if muscle E4 plays a necessary role in feeding behavior, we lesioned the muscle unilaterally or bilatcrally, and cxamincd the feeding responses of animals. Wc found that lesioned animals could still show both biting and swallowing responses. Furthermore, we obtained a measure of feeding efficiency by feeding the animals seaweed strips of 2 sizes $(0.5 \times 8 \mathrm{~cm}$ or $1 \times 8 \mathrm{~cm})$ and measuring the time it took them to eat the strips. In a pilot study with 3 lesioned animals (one with the right E4 lesioned, one with the left E4 lesioned, and one with both E4s lesioned), and with 2 sham controls, we did not observe any consistent difference between the groups.

To test whether the combination of E4 and E5 was necessary for feeding, both muscles were lesioned bilaterally and the effects on several parameters of feeding behavior were studied. On the preoperative day, the following parameters were measured in all animals: (1) the mean interbite interval for 6 successive bites in which the animals were not permitted to ingest the food; (2) the mean magnitude of each of the 6 bites (measured on a scale of 1 to 4); (3) the latency to the first swallow of a $1 \times 8 \mathrm{~cm}$ strip of seaweed; (4) the time taken to consume the entire strip; and (5) the number of swallows required to consume the strip. The last 3 measurements were repeated for a second seaweed strip. Parameters (4) and (5) were then used to compute 2 variables of prime interest: $\left(4^{\prime}\right)$ the average interswallow interval (swallow time divided by the number of swallows minus one, averaged over the 2 strips), and $\left(5^{\prime}\right)$ the average swallow amount per bite [average amount of seaweed in each strip $(47 \pm 6.1 \mathrm{mg}$ standard deviation) divided by the number of swallows, averaged over the 2 strips].

On the basis of a pretest, 11 pairs of animals were matched for weight, number of swallows, and time to injest the strips of seaweed. Under magnesium chloride anesthesia, a randomly selected animal of each pair received a lesion, and its paired control received a sham lesion. In experimental animals, muscles E4 and E5 were visualized. They were severed bilaterally, and sections of each were removed to retard possible regeneration and reattachment. In sham-lesioned animals, the muscles were exposed but not damaged. The incisions in all animals were then sutured, and they were replaced in individual holding chambers to recover. The behavioral tests described above for the pretest were then repeated for each animal for 4 postoperative days by an investigator who was blind to the treatments each animal had received. Two animals failed to respond on the first postoperative day, and were therefore excluded from the remainder of the experiment. Thus, there was a final $N$ of 10 animals in each group. The temperature of the tank on the preoperative day, and on postoperative days $1-3$, was $16.5 \pm$ $1^{\circ} \mathrm{C}$. On day 4 , the tank temperature was lowered to $13.5^{\circ} \mathrm{C}$ to explore the effects of a lower temperature on the response of the animals. Prior experiments (Rosen et al., 1983) had indicated that animals are often debilitated on the day after head surgery, and we therefore excluded postoperative day 1 data from all statistical analyses.

Since we had no a priori reason to assume that the animals' behaviors would be stable from day to day, we chose to test the differences between the 2 groups [using variables (1), (2), (4'), and $\left(5^{\prime}\right)$, as described above] on each day separately, using Hotelling's T-squared statistic (Tatsuoka, 1971) for multiple variables. Hotelling's T-squared was determined separately for days $2-4$, and the level of significance $(0.05)$ was appropriately adjusted $(p=0.05 / 3=0.017)$ for multiple tests using the Bonferroni criterion (Miller, 1981). The 2 groups did not differ significantly on day 2 (T-squared $=3.2, F(4,15)=0.68, p=0.62$ ), day $3(\mathrm{~T}$-squared $=1.98, F(4,15)=0.4, p=0.8)$, or day 4 (Tsquared $=9.6, F(4,15)=2.0, p=0.14)$. The average swallow amount for the lesioned animals was less than that for the control animals on each postoperative day, but this tendency was not statistically significant (Fig. 25).

On day 4 , when the tank temperature was lowered, animals in both groups showed an increase in interbite and interswallow intervals, and a greater difference in their average swallow amount. It is possible, therefore, that when animals are feeding more slowly, as they do in colder temperatures, muscles E4 and E5 may contribute more to the efficiency of their feeding. Hotelling's T-squared statistic for day 4 failed to reach statistical significance, but the data revealed a clear trend for a decreased swallow amount per bite for the lesioned animals, whereas all other variables were similar for the 2 groups.

Since lesioning extrinsic muscles E4 and E5 had, at best, only a slight effect on feeding efficiency, we tested whether lesioning all the extrinsic muscles affected feeding. Two groups, containing 10 and 12 animals, respectively, were studied. During surgery, one animal contracted and was discarded. We also excluded from analysis any animals that failed to swallow on the first postoperative day, since they had consumed 2 fewer seaweed strips than the other animals and might be in a different state of arousal. Thus, our final group contained 7 animals in the lesion group, and 7 in the sham control group. Animals were tested as described above. In experimental animals, muscles E1, E2, E3, E4, E5, and E6 were visualized, and sections of each were removed bilaterally. In sham lesion animals, the muscles were exposed but were not damaged. The same statistical measures were used to assess the differences between the 2 groups on the 4 parameters described above on postoperative days $2-4$.

Hotelling's T-squared indicated that experimental and control 


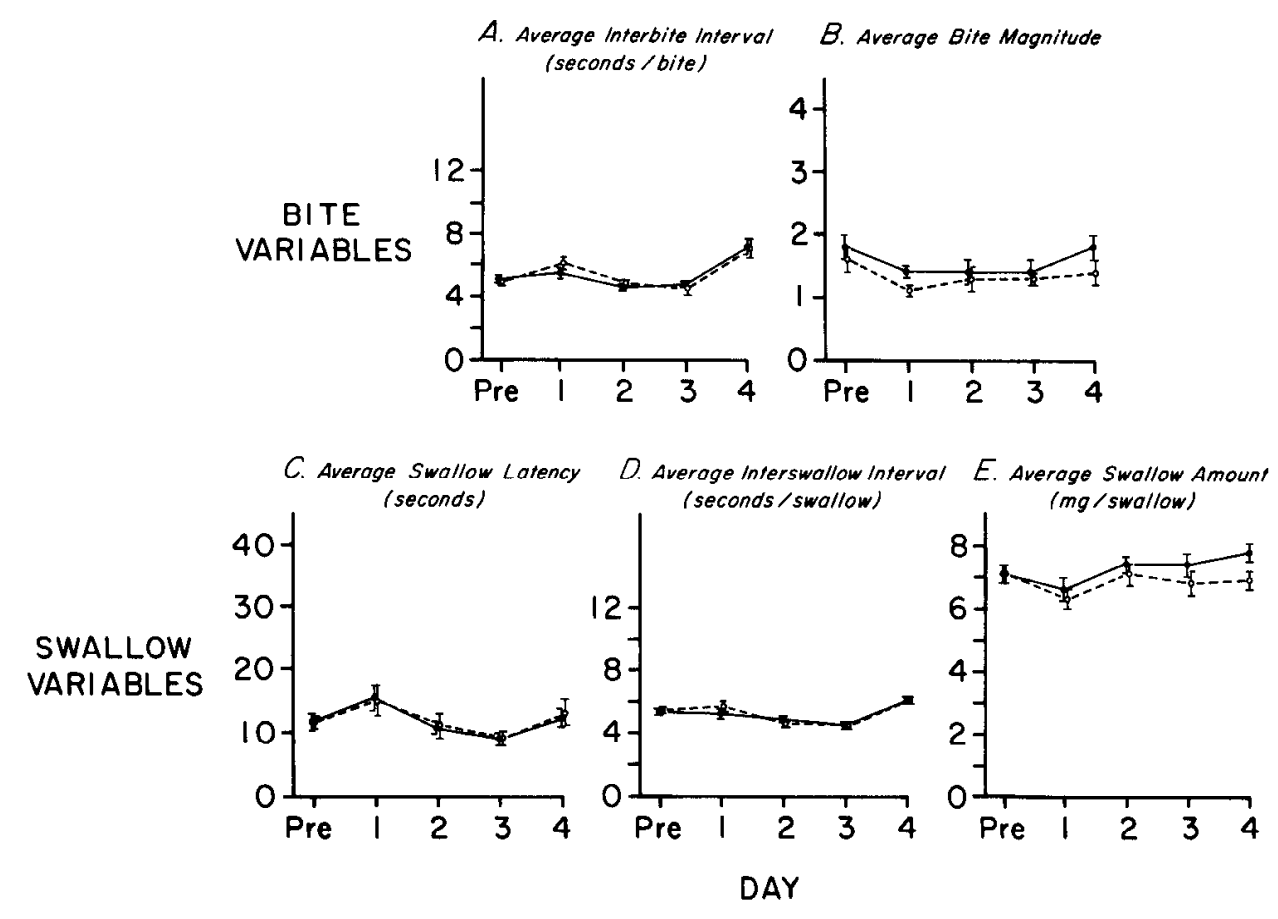

Figure 25. Effect of lesions of extrinsic buccal muscles E4 and E5 on feeding efficiency. Experimental animals were subjected to bilateral lesions of extrinsic buccal muscles E4 and E5; control animals received sham lesions. $N=10$ in each group. Data are graphed as means \pm SEM. Note differences in scale for different variables. Statistical tests were performed on all postoperative days, excluding day 1 . $A$, Average interbite interval represents the mean interbite interval for 6 successive bites in which the animals were not permitted to ingest food. Differences between the groups are not significant on any day. Note that on the fourth day, when the tank temperature is lowered, both groups show an increase in the interbite interval. $B$, Average magnitude represents the mean bite magnitude for 6 successive bites, measured on a scale of 1 to 4 . Differences between the groups are not significant on any day. $C$, Average swallow latency represents the time from the first contact of an animal with a seaweed strip until its first swallow. The data represent the average swallow latencies for 2 strips of seaweed. Differences between the groups are not significant on any day. Note that on the fourth day, when the tank temperature is lowered, both groups show an increase in swallow latency. $D$, Average interswallow interval represents the time to swallow a seaweed strip divided by the number of swallows minus one, averaged over 2 strips. Differences between the groups are not significant on any day. Note that on the fourth day, when the tank temperature is lowered, both groups show an increase in interswallow interval. $E$, Average swallow amount represents the average amount of seaweed in each strip (47 mg) divided by the number of swallows, averaged over 2 strips. Lesioned animals had smaller average swallow amounts on each day, but the differences were not significant on any day. The difference was accentuated on day 4 , but failed to reach statistical significance.

groups differed on one or more variables for days 2 and 3 (Tsquared, day $2=31.1, F(4,9)=5.83, p=0.013 ;$ T-squared, day $3-46.5, F(4,9)=8.72, p=0.004)$. The scores cxhibited the same general pattern on day 4 , but the differences failed to reach significance (T-squared $=9.83, F(4,9)=1.84, p=0.20$ ). It is not clear why the data failed to reach significance on day 4 , but this was apparently due to the unusually long time it took some control animals to swallow the strips on day 4 . This could have resulted from the generalized deterioration of those animals, or to some other uncontrolled variable.

We analyzed the data of days 2 and 3 in more detail. Inspection of the data (Fig. 26) revealed a consistent pattern in which, compared to controls, the animals with lesions of the extrinsic musculature exhibited a decrease in both average bite magnitude and average amount ingested per swallow. However, only selected comparisons reached statistical significance. This was probably due to the small size of the differences and the large variability of the data. Furthermore, since we wished to make multiple comparisons, we used a very strict criterion for statistical significance. The criterion level, 0.017 , associated with each Hotelling's T-squared statistic, was further subdivided by the number of tests we wished to do, with 4 (sham control vs. lesion values for each of the 4 variables) resulting in a new criterion level of $0.017 / 4=0.0042$ (Miller, 1981). Using this criterion, statistical significance was reached for bite magnitude on day 2 (lesioned: $2.26 \pm 0.21 \mathrm{SEM}$; control: $3.18 \pm 0.15 ; t=$ $3.5, p<0.004)$, and for average amount ingested per swallow on day 3 (lesioned: $4.7 \pm 0.3 \mathrm{mg} /$ swallow; control: $6.4 \pm 0.4$ $\mathrm{mg} / \mathrm{swallow} t=3.66, p<0.003$ ). Large but nonsignificant $t$ values were obtained for amount ingested per swallow on day $2(t=2.62, p<0.02)$, and for bite magnitude on day $3(t=$ $2.97, p<0.01$ ). Although lesions of extrinsic muscles resulted in a small and insignificant increase in the interswallow interval, it should be noted that lesioned animals required a greater number of swallows and an increased total time to swallow a fixed amount of seaweed. These changes in the feeding efficiency of lesioned animals were due to the smaller average amount of seaweed they ingested with each swallow. Thus, our data indicate that (1) the extrinsic muscles are not necessary for the execution of either biting or swallowing responses, and (2) the presence of these muscles contributes to feeding efficiency by increasing the amount of seaweed an animal can ingest with each swallow.

\section{Discussion}

The present results indicate that $\mathrm{C} 2$ has functional roles beyond those mediated by its excitatory connections to the MCC. We have shown that (1) neurons in the cerebral E cluster that receive synaptic input from $\mathrm{C} 2$ also receive inputs from buccal "feeding programs"; (2) several of the synaptic followers of C2 evokc reliable muscle contractions, and are presumptive motor neurons; (3) $\mathrm{C} 2$ can modulate the motor outputs of its followers through its excitatory and inhibitory connections to them; (4) $\mathrm{C} 2$ excites a modulatory motor neuron that is capable of acting 


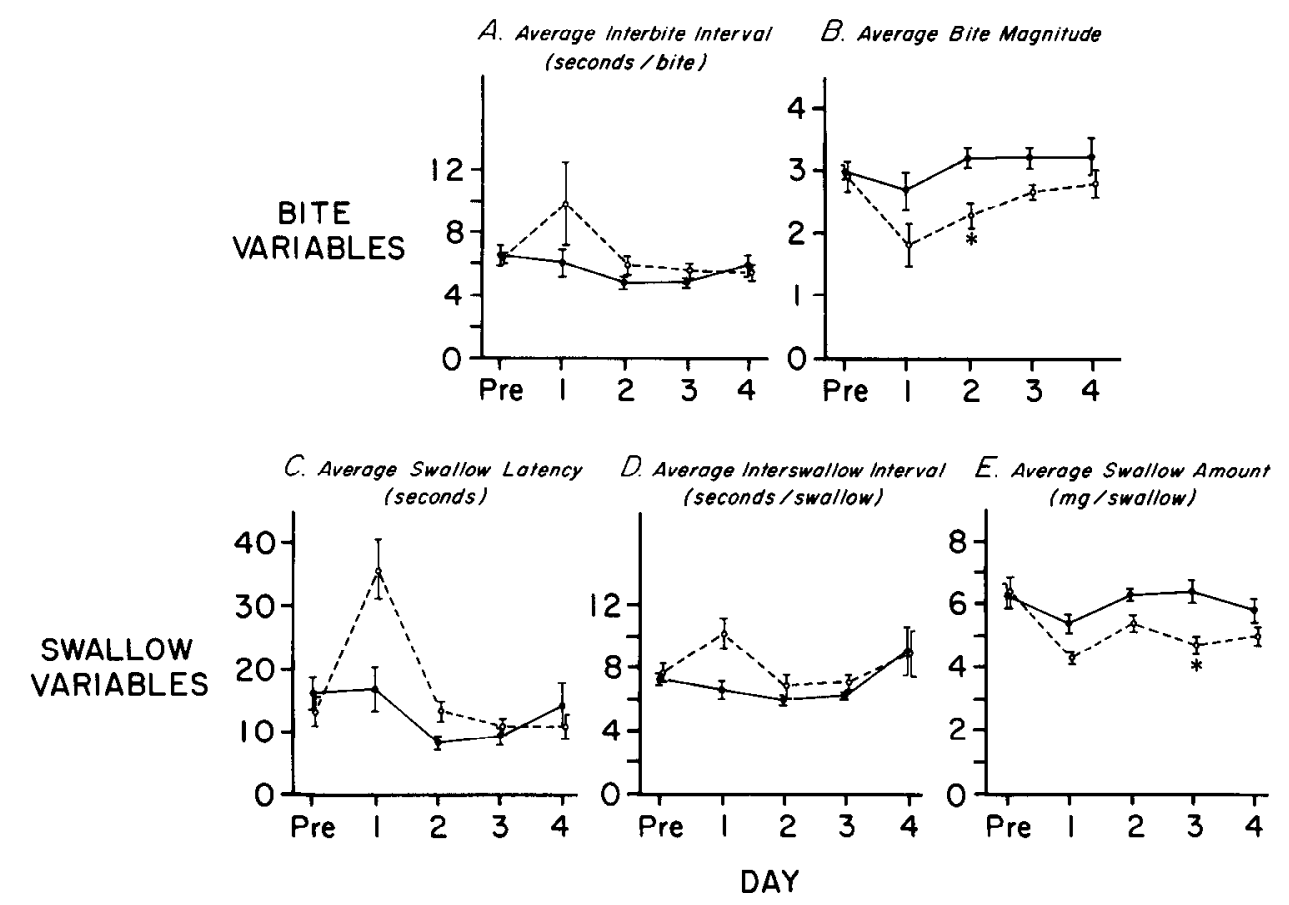

Figure 26. Effect of lesions of all the extrinsic muscles on feeding efficiency. Experimental animals were subjected to bilateral lesions of extrinsic buccal muscles E1-E6; control animals received sham lesions. $N=7$ in each group. Data are graphed as means \pm SEM. Note differences in scales for different variables. Statistical tests were performed for all postoperative days except for day 1 . $A$, Average interbite interval represents the mean interbite interval for 6 successive bites in which the animals were not permitted to ingest food. Differences between the groups are not significant on any day. $B$, Average bite magnitude represents the mean bite magnitude for 6 successive bites, measured on a scale of 1 to 4 . The lesioned group showed significantly smaller bite magnitudes on the second postoperative day, and showed a similar trend on the other days. $C$, Average swallow latency represents the time from the first contact of an animal with a seaweed strip until its first swallow. The data represent the average swallow latencies for 2 strips of seaweed. Differences between the groups are not significant on any day. $D$, Average interswallow interval represents the time to swallow a seaweed strip divided by the number of swallows minus one, averaged over 2 strips. Differences between the groups are not significant on any day. $E$. Average swallow amount represents the average amount of seaweed in each strip (47 mg) divided by the number of swallows, averaged over 2 strips. The lesioned group ingested a significantly smaller amount of seaweed with each swallow on the third postoperative day, and showed a similar trend on the other days.

in the periphery to inhibit muscle contractions evoked by activity of other synaptic follower cells of $\mathrm{C} 2 ;(5)$ the muscles upon which $\mathrm{C} 2$ and its followers exert their effects are phasically activated during feeding behavior; and (6) the extrinsic buccal musculature, which includes several muscles modulated by $\mathrm{C} 2$, contributes to the efficiency of swallowing.

\section{C2 functions as a premotor neuron}

Our studies were designed to explore the functions of the output of $\mathrm{C} 2$ other than its connection to the MCC. Since C2 sends axons to the periphery (Weiss et al., 1986c), and also makes synaptic connections to a large number of neurons in the cerebral ganglion (McCaman and Weinreich, 1982; Ono and McCaman, 1980; Weinreich, 1977), we sought to address the following 3 questions: (1) Is $\mathrm{C} 2$ a command neuron that generates specific patterns of motor output? (2) Is it a motor neuron or a premotor neuron? (3) Does it have broad effects on a variety of behaviors, consistent with its being an element of a central arousal system, or are its actions related more specifically to one particular behavior? In the discussion that follows, we argue that $\mathrm{C} 2$ functions as a premotor neuron that has 2 classes of action. First, it has a slow tonic action which sets the general excitatory level of muscles and neurons involved in the consummatory phase of feeding. Second, it has a fast, phasic action which can reinforce specific components of feeding movements.

Our studies suggest that $\mathrm{C} 2$ is not a command neuron, since its activity does not appear to be necessary or sufficient for any coordinated behavioral responses (Kupfermann and Weiss, 1978). Furthermore, although C2 sends axons to the periphery, there is no evidence that it is a motor neuron. Firing of $\mathrm{C} 2$ does not cause any short-latency, reliable contractions. Those contractions that occur when $\mathrm{C} 2$ is fired at high frequency appear to be caused by the polysynaptic excitation of other neurons, including identified neuron $\mathrm{C6}$, which is a powerful motor neuron for extrinsic buccal muscles E4 and E5. These observations support our previous conclusions that $\mathrm{C} 2$ is a proprioceptive afferent, and that the axons of $\mathrm{C} 2$ actually conduct toward the cerebral ganglion. The peripheral processes of $\mathrm{C} 2$ are activated in phase with feeding movements of the buccal mass and respond to mechanical stimuli occurring at the juncture of the jaws and lips of the animal (Weiss et al., 1986c; see also Fig. 14).

\section{Tonic effects of C2}

Although the findings of this paper, as well as previous results, indicate that $\mathrm{C} 2$ fires in a highly phasic manner, its effects, as mediated by the MCC, are tonic and contribute to the overall excitability of feeding behavior. This is a consequence of the very slow rise and fall time of the EPSP that $\mathrm{C} 2$ produces on the MCC (Weiss et al., 1986a). Also, the modulatory effects of the MCC on buccal muscles and central neurons are themselves very slow and accumulate over several cycles of contraction of buccal muscles (Weiss et al., 1978).

\section{Phasic modulatory motor actions of $\mathrm{C} 2$}

Figure 27 illustrates (dark lines) the types of connections C2 makes to neurons other than the MCC. It acts at the level of either excitatory or inhibitory motor neurons. Studies presented 


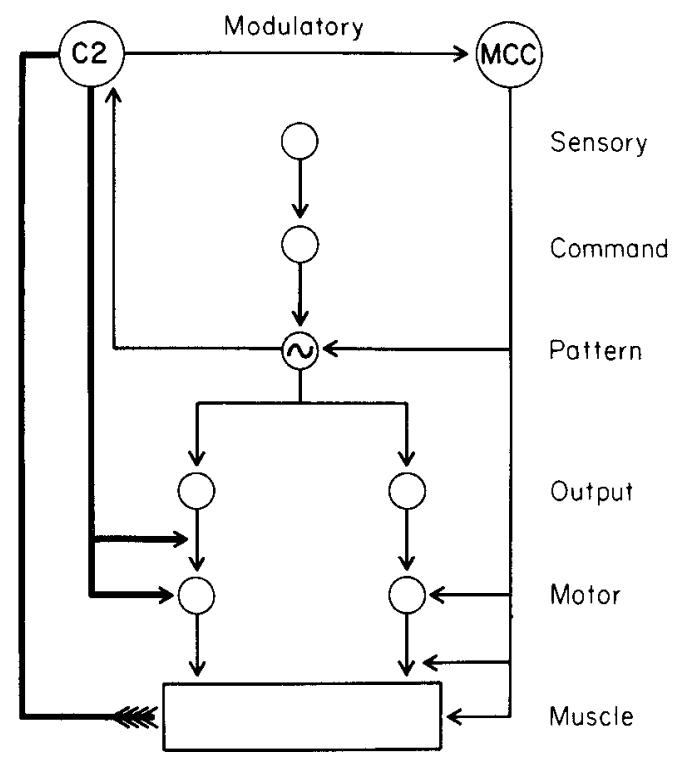

Figure 27. Schematic diagram illustrating levels of control of circuits involved in the consummatory phase of feeding behavior. The connections of $\mathrm{C} 2$ to neurons other than the MCC (dark lines) are made at 2 levels of the circuit: at inhibitory and excitatory motor neurons, and at buccal neurons that provide an output (to the cerebral ganglion) of a feeding motor program generated in the buccal ganglion (see Chiel et al., 1982, and unpublished observations).

elsewhere (Chiel et al., 1982, unpublished observations) also indicate that $\mathrm{C} 2$ can produce monosynaptic presynaptic inhibition of buccal-cerebral interneurons that convey to the cerebral ganglion a corollary discharge of the feeding motor program generated in the buccal ganglion (see also Davis et al., 1973; Jahan-Parwar and Fredman, 1983). In addition to the general enhancement of feeding behavior $\mathrm{C} 2$ causes by means of its connection to the MCC, 4 lines of evidence indicate that the non-MCC connections of $C 2$ may have actions that reinforce a central feeding motor program, and help to shape the outputs of muscles related to feeding by phasically shifting the gain, timing, and phasing of neural activity. First, the activity of $\mathrm{C} 2$ is tightly phase-locked to buccal mass movements, and, in fact, C2 receives fast phasic inhibitory potentials that can sharpen its outputs. Second, despite the slow nature of its synaptic connections, $\mathrm{C} 2$ is capable of causing relatively rapid alterations in the activity of some motor neurons. When the motor neuron for body-wall muscle (BW1) fires rapidly, C2 can dramatically reducc its activity and rclax the musclc (sec Fig. 6). Similarly, although the excitatory synaptic potential that $\mathrm{C} 2$ produces in motor neuron $\mathrm{C} 6$ has a slow onset (see Fig. 5), C2 has a relatively phasic excitatory effect, since it simultaneously and rapidly suppresses inhibitory inputs to C6 (see Fig. 7). Third, C2 can act to alter the strength, and thus shift the phase, of the powerful synaptic inputs that impinge on its followers and that come from feeding motor programs in the buccal ganglion (Chiel et al., 1982, unpublished observations). Fourth, the phasic activation of $\mathrm{C} 2$ may allow it to accelerate the contraction and relaxation of extrinsic muscles E4 and E5. During the beginning of retraction, it can accelerate the contraction of E4 and E5 through its slow excitatory connection to $\mathrm{C} 6$, a motor neuron for those muscles (see Fig. 7); later in the swallowing cycle, during the beginning of protraction, $\mathrm{C} 2$ can accelerate the relaxation of muscles E4 and E5 through its slow excitatory connection to $\mathrm{C} 4$ (see Fig. 3), a neuron that acts to relax the muscles (Figs. 5, 9-11) and that also receives powerful excitation from the buccal ganglion during this phase of behavior (see Figs. 14, $15)$.
The phasic motor actions of $\mathrm{C} 2$, together with the fact that its activity is gated by internal and external conditions, may contribute to the phenomenon of motor constancy (Berkinblit et al., 1986), in which proprioceptive information is utilized so that a fixed motor goal can be reached, regardless of variations of the position of an appendage (or of the odontophore, in the case of gastropod feeding). In addition, since the excitation of C2 (Weiss et al., 1986c) and of muscles E4 and E5 increase as a function of the mechanical stimulation of the jaws and perioral zone (see Fig. 24), it is possible that C2 and some of its synaptic followers may help an animal respond appropriately to changes in the toughness or texture of food. Indeed, other studies (Susswein and Schwarz, 1983) indicate that Aplysia are capable of sensing the toughness of food, and may use this information to learn to reject foods that are too tough to swallow.

\section{The extrinsic muscles as "platform" or "postural" muscles}

The synaptic followers of $\mathrm{C} 2$ that we have identified in the $\mathrm{E}$ cluster have properties that suggest that $\mathrm{C} 2$ may selectively reinforce a specific phase of feeding, namely, retraction during swallowing. These follower neurons are either motor neurons ( $\mathrm{C} 6$, C7) or modulatory motor neurons (C4) that receive powerful synaptic inputs, which appear to be "readouts" of feeding motor programs emanating from the buccal ganglion (see Fig. 14). Further, the follower neurons act upon muscles (E4, E5, BW1) that are active in phase with buccal mass movements during feeding behavior (see Figs. 22, 23, and 6D).

In order to understand the actions of $\mathrm{C} 2$ and its synaptic followers on the extrinsic muscles, we will discuss the evidence supporting the hypothesis that these muscles function, in general, as "platform" or "postural" muscles that enhance feeding behavior; we will then describe the evidence in support of the hypothesis that muscles E4 and E5 specifically act to enhance the retraction phase of swallowing.

Although the extrinsic muscles we have studied are active during different phases of buccal mass movement, they are not necessary for feeding behavior. E4 and E5 exhibit phasic electrical activity during swallowing and rejection (Figs. 22, 23), and muscle E1 receives input during biting as well (Fig. 20), but lesions of all the extrinsic muscles do not prevent animals from biting and swallowing (Fig. 26). These data suggest that the extrinsic buccal muscles may provide the appropriate background for feeding movements, and are less involved in the generation of the gross movements themselves. It is well known that in vertebrate motor systems, a substantial proportion of the motor output of the CNS is devoted to regulation of muscles that are not involved in so-called transport functions that result in the direct production of specific movements (Cordo and Nashner, 1982; Fitch ct al., 1982; Marsden et al., 1981), but instead mediate "platform" and postural responses. Gastropod mollusks lack a skeleton and joints, which can serve as natural fulcra for movements. Thus, the muscles of gastropods must not only provide forces to generate movement, but must also have a major role in providing the "skeleton" or "platform" against which movements are generated (see Harris-Warrick and Kravitz, 1984, for a discussion of the role of biogenic amines in modulating postural responses in crustacea).

Our data suggest more specifically that extrinsic muscles E4 and E5 may be a part of a muscular system that enhances the retraction or backward rotation phase of swallowing: (1) Extracellular recordings from the muscles revealed that they receive intense excitatory input at the peak of the inward phase of swallowing (see Figs. 22, 23), which corresponds to the peak retraction of the buccal mass (Weiss et al., 1986b). In contrast, the muscles receive little or no input during biting, when the animal is not given an opportunity to grasp and swallow food (see Figs. 22, 23). Under these conditions, the movements are characterized by strong protractions of the buccal mass, but 
weak retractions. During rejection, which is also characterized by strong protractions and weaker retractions (see Fig. 16), the muscles may actually receive inhibitory inputs (see Figs. 22, 23). (2) Bilateral lesions of muscles E4 and E5 appear to reduce the average swallow amount, i.e., the amount of seaweed ingested per swallow, which could reflect decreased efficiency in retraction and associated responses.

The anatomy of the muscles, however, indicates that they do not enhance retraction by pulling the buccal mass further back. Instead, their attachments are such that the muscles might act to enhance the coupling of the jaws and buccal mass to the head of the animal, which could provide a stiffer platform against which movements could be generated. Observations in dissected animals suggest that such an anchor point, which counteracts forces generated by the esophagus and the roof of the buccal cavity during the peak of swallowing, might aid in elongation of the buccal mass, and thus enhance the backward movement of the radula at the peak of swallowing (see Fig. 7, Weiss et al., 1986b). Thus, E4 and E5 provide a specific example of muscles that serve to modulate, rather than directly mediate, feeding movements. Contraction of body-wall muscle BW1 might also provide stiffening of head muscles that can aid swallowing responses.

\section{$C 2$ and a central arousal system}

Can $\mathrm{C} 2$ be regarded as an element of a central arousal system? Our research on the neural organization of feeding in Aplysia has been guided by a model that postulates 2 distinct classes of modulatory neurons (Kupfermann and Weiss, 1981). One class, represented by neurons such as the heart excitor $\mathrm{RB}_{\mathrm{HE}}$ (Mayeri et al., 1974) and the MCC, has highly specific actions. The effect of each of these neurons is limited to one behavior or a component of a behavior. Neurons of this class execute the actions of a second class, which is postulated to consist of neurons that constitute a central arousal system. This system has a mnemonic function (it maintains the arousal state) and exerts highly general effects, influencing many varieties of behavior.

One of the aims of the present series of studies (Weiss et al., $1986 \mathrm{a}-\mathrm{c}$ ) has becn to identify clements of the putative central arousal system of Aplysia. The data from the preceding papers indicate that $\mathrm{C} 2$ has at least some of the properties appropriate for an idealized element of a central arousal system. $\mathrm{C} 2$ is activated by food, a stimulus that behaviorally arouses the animal; it excites the MCC, an important neuronal element which expresses aspects of a food arousal state by enhancing consummatory responses involving the intrinsic muscles of the buccal mass; and feeding movements activate $\mathrm{C} 2$ as part of a positive feedback loop, so that its activity persists beyond the time of presentation of the initiating stimulus (i.e., food).

Another important feature expected of a central arousal element, however, is that it should have divergent or generalized output (Andrew, 1974; Fentress, 1973). The results presented in this paper indicate that the effects of $\mathrm{C} 2$ appear to be broader than those of the MCC, but narrower than what might be expected of an element of a central arousal system. The behavioral role of $\mathrm{C} 2$ extends beyond its function of exciting the $\mathrm{MCC}$, and thereby regulating the intrinsic buccal muscles involved in feeding. We found that several of the neurons that receive synaptic input from $\mathrm{C} 2$ have either excitatory or inhibitory actions on the extrinsic muscles of the buccal mass. These follower cells, and the extrinsic buccal muscles, receive synaptic input during bursts of "feeding motor programs" generated by the buccal ganglion, particularly during swallowing and rejection. $\mathrm{C} 2$ also modulates a neuron that excites a hody-wall muscle that is not directly connected to the buccal mass, but that appears to be phasically active during buccal movements. Although $\mathrm{C} 2$ has a variety of effects, it appears to be largely, if not exclusively, concerned with one or another aspect of feeding, and we have no evidence that it is involved in any of the other behaviors associated with food arousal, such as alterations of locomotion and cardiovascular responses. It is possible, of course, that these effects are mediated by connections of $\mathrm{C} 2$ that we have not found, or have not activated in conditions appropriate for their functional expression.

Our findings on $\mathrm{C} 2$ suggest the possibility that the nervous system of Aplysia may not consist of modulatory elements that fall into a convenient dichotomy consisting of one class with very general effects, and a second class with highly specific effects. Instead, modulatory neurons may consist of a continuum of types that vary in their degree of specificity. Indeed, a central arousal system may consist of such a continuum of modulatory neurons, rather than a discrete set of neurons dedicated solely to general arousal. It is interesting that in vertebrates, the reticular activating system, which was postulated to be a central arousal system, is now known to consist of different systems of neurons with broad but differential actions (Hobson and Brazier, 1980).

\section{C2 is an integrative proprioceptive neuron}

The data presented in this series of studies indicate that $\mathrm{C} 2$ is a proprioceptive afferent, and that it has some similarity to the function of other proprioceptors in Aplysia (Cohen and Kupferman, 1971; Jahan-Parwar et al., 1983), in other invertebrates (Altman and Tyrer, 1977; Burrows, 1976; Kristan and Stent, 1974; Pearson, 1982; Pearson et al., 1983, Wendler, 1974), and in vertebrates (e.g., Pearson and Duysens, 1976). For example, similar to $\mathrm{C} 2$, wing proprioceptors on the locust have both nonspecific effects on wing-beat frequency (Wilson and Gettrup, 1963), as well as more specific effects that serve to reinforce the central flight program and modify it in response to altered peripheral loads (Pearson et al., 1983; Waldron, 1967). Like those receptors, C2's receptive field (the perioral zone) is close to the site of attachment of some of the muscles upon which $\mathrm{C} 2$ acts (muscles E4 and E5). C2, however, not only conveys proprioceptive information, but also appears to have a major integrative role. We hypothesize that the synaptic outputs of this neuron can be gated on or off as a function of both the internal state of the animal, such as its satiation level, and environmental conditions, such as the physical properties of the food it ingests. It will be of interest to determine how general this type of function may be.

\section{References}

Altman, J. S., and N. M. Tyrer (1977) The locust wing hinge stretch receptors. I. Primary sensory neurones with enormous central arborizations. J. Comp. Neurol. 172: 409-430.

Andrew, R. J. (1974) Arousal and the causation of behavior. Behaviour 51: 135-165.

Beltz, B., and A. Gelperin (1980) Mechanisms of peripheral modulation of salivary burster in Limax maximus: A presumptive sensorimotor neuron. J. Neurophysiol. 44: 675-686.

Berkinblit, M. B., A. G. Feldman, and O. I. Fukson (1986) Adaptability of innate motor patterns and motor control mechanisms. Behav. Brain Sci. (in press).

Bolles, R. C. (1967) Theory of Motivation, Harper and Row, New York.

Brace, R. C., and D. L. J. Quicke (1981) Activity patterns in radular retractor motoneurones of the snail, Planorbarius. J. Comp. Physiol. A 142: 259-270.

Burrows, M. (1976) Neural control of flight in the locust. In Neural Control of Locomotion, R. M. Herman, S. Grillner, P. S. G. Stein, and D. G. Stuart, eds., pp. 419-438, Plenum, New York.

Chiel, H. J., K. R. Weiss, and I. Kupfermann (1982) An identified histaminergic neuron modulates lip and mouth feeding movements in Aplysia. Soc. Neurosci. Abstr. 8: 823. 
Cohen, J. L., and I. Kupfermann (1971) The control of feeding by identified neurons in the buccal ganglion of Aplysia. Am. Zool. 11: 667.

Cordo, P. J., and L. M. Nashner (1982) Properties of postural adjustments associated with rapid arm movements. J. Neurophysiol. 47: $287-302$.

Croll, R. P., and W. J. Davis (1981) Motor program switching in Pleurobranchaea. I. Behavioural and electromyographic study of ingestion and egestion in intact specimens. J. Comp. Physiol. 145: 277-287.

Cuvier, G. (1803) Memoires pour servir a l'histoire et l'anatomie des mollusques. Sur le genre Aplysia, vulgairement nommé Lièvre marin; sur son anatomie, et sur quelques-unes de ses espèces. Ann. Mus. Nat. Hist. Paris 2: 287-314.

Davis, W. J., M. V. S. Siegler, and G. J. Mpitsos (1973) Distributed neuronal oscillators and efference copy in the feeding system of Pleurobranchaea. J. Neurophysiol. 36: 258-274.

Fentress, J. C. (1973) Specific and nonspecific factors in the causation of behavior. In Perspectives in Ethology, P. P. G. Bateson and P. H. Klopfer, eds., pp. 154-224, Plenum, New York:

Fitch, H. L.; B. Tuller, and M. T. Turvey (1982) The Bernstein Perspective. III. Tuning of coordinative structures with special reference to perception. In Human Motor Behavior: An Introduction. J. A. Kelso, ed., pp. 271-281, Lawrence Erlbaum, Hillsdale, NJ.

Harris-Warwick, R. M., and E. A. Kravitz (1984) Cellular mechanisms for modulation of posture by octopamine and serotonin in the lobster. J. Neurosci. 4: 1976-1993.

Hobson, J. A., and M. A. B. Brazier (eds.) (1980) The Reticular Formation Revisited: Specifying Function for a Nonspecific System, International Brain Research Organization (IBRO) Monograph Series, Vol. 6, Raven, New York.

Howells, H. H. (1942) The structure and function of the alimentary canal of Aplysia punctata. Q. J. Microscop. Sci. 83: 357-397.

Jacklet, J. W., and J. Rine (1977) Facilitation at neuromuscular junctions: Contribution to habituation and dishabituation of the Aplysia gill withdrawal reflex. Proc. Natl. Acad. Sci. USA 74: 1267-1271.

Jahan-Parwar, B., and S. M. Fredman (1976) Cerebral ganglion of Aplysia: Cellular organization and origin of nerves. Comp. Biochem. Physiol. 54A: 347-357.

Jahan-Parwar, B., and S. M. Fredman (1983) Control of extrinsic feeding muscles in Aplysia. J. Neurophysiol. 49: 1481-1503.

Jahan-Parwar, B., A. H. Wilson, Jr., and S. M. Fredman (1983) Role of proprioceptive reflexes in control of feeding muscles of Aplysia. J. Neurophysiol. 49: 1469-1480.

Kristan, W. B., Jr., and G. Stent (1974) Peripheral feedback in the leech swimming rhythm. Cold Spring Harbor Symp. Quant. Biol. 40: 663-674.

Kupfermann, I. (1974) Feeding behavior in Aplysia: A simple system for the study of motivation. Behav. Biol. 10:1-26.

Kupfermann, I., and H. Pinsker (1968) A behavioral modification of the feeding reflex in Aplysia californica. Commun. Behav. Biol. A 2: $13-17$.

Kupfermann, I., and K. R. Weiss (1978) The command neuron concept. Behav. Brain Sci. 1: 3-39.

Kupfermann, I., and K. R. Weiss (1981) The role of serotonin in arousal of feeding behavior of Aplysia. In Serotonin Neurotransmission and Behavior, A. Gelperin and B. Jacobs, eds., pp. 255-287, M.I.T. Press, Cambridge, MA

Marsden, C. D., P. A. Merton, and H. B. Morton (1981) Human postural responses. Brain 104: 513-534.

Mayeri, E., J. Koester, I. Kupfermann, G. Liebeswar, and E. R. Kandel (1974) Neural control of circulation in Aplysia: I. Motoneurons. J. Neurophysiol. 37: 458-475.

McCaman, R. E., and D. Weinreich (1982) On the nature of histamine- mediated slow hyperpolarizing synaptic potentials in identified molluscan neurones. J. Physiol. (Lond.) 328: 485-506.

McCaman, R. E., and D. Weinreich (1985) Histaminergic synaptic transmission in the cerebral ganglion of Aplysia. J. Neurophysiol. 53: 1016-1037.

Miller, R. G., Jr. (1981) Simultaneous Statistical Inference, 2nd Ed., Springer-Verlag, New York.

Ono, J. K., and R. E. McCaman (1980) Identification of additional histaminergic neurons in Aplysia: Improvement of single cell isolation techniques for in tandem physiological and chemical studies. Neuroscience $5: 835-840$.

Pearson, K. G. (1982) Neural circuits for jumping in the locust. J. Physiol. (Paris) 78: 765-771.

Pearson, K. G., and J. Duysens (1976) Function of segmental reflexes in the control of stepping in cockroaches and cats. In Neural Control of Locomotion, R. M. Herman, S. Grillner, P. S. G. Stein, and D. G. Stuart, eds., Plenum, New York.

Pearson, K. G., D. N. Reye, and R. M. Robertson (1983) Phasedependent influences of wing stretch receptors on flight rhythm in the locust. J. Neurophysiol. 49: 1168-1181.

Peters, M., and U. Altrup (1984) Motor organization in pharynx of Helix pomatia. J. Neurophysiol. 52: 389-409.

Ram, J. L., U. A. Shukla, R. Parti, and R. L. Goines (1984) Extracellular calcium dependence of contracture and modulation by serotonin in buccal muscle El of Aplysia. J. Neurobiol. 15: 197-206.

Rosen, S. C., K. R. Weiss, J. L. Cohen, and I. Kupfermann (1982) Interganglionic cerebral-buccal mechanoafferents of Aplysia: Receptive fields and synaptic connections to different classes of neurons involved in feeding behavior. J. Neurophysiol. 48: 271-288.

Rosen, S. C., I. Kupfermann, R. S. Goldstein, and K. R. Weiss (1983) Lesion of a serotonergic neuron in Aplysia produces a specific deficit in feeding behavior. Brain Res. 260: 151-155.

Stewart, W. W. (1978) Functional connections between cells as revealed by dye-coupling with a highly fluorescent naphthalimide tracer. Cell 14: 741-759.

Susswein, A. J., and M. Schwarz (1983) A learned change of response to inedible food in Aplysia. Behav. Neural Biol. 39: 1-6.

Susswein, A. J., K. R. Weiss, and I. Kupfermann (1978) The effects of food arousal on the latency of biting in Aplysia. J. Comp. Physiol. 123: 31-41.

Tatsuoka, M. M. (1971) Multivariate Analysis: Techniques for Educational and Psychological Research, Wiley, New York.

Waldron, I. (1967) Neural mechanism by which controlling inputs influence motor output in the flying locust. J. Exp. Biol. 47: 213-228.

Weinreich, D. (1977) Synaptic responses mediated by identified histamine-containing neurones. Nature 267: 854-856.

Weiss, K. R., J. L. Cohen, and I. Kupfermann (1978) Modulatory control of buccal musculature by a serotonergic neuron (metacerebral cell) in Aplysia. J. Neurophysiol. 41: 181-203.

Weiss, K. R., E. Shapiro, and I. Kupfermann (1986a) Modulatory synaptic actions of an identified histaminergic neuron on the serotonergic metacerebral cell of Aplysia. J. Neurosci. 6: 2393-2402.

Weiss, K. R., H. J. Chiel, U. T. Koch, and I. Kupfermann (1986b) Activity of an identified histaminergic neuron, and its possible role in arousal of feeding behavior in semi-intact Aplysia. J. Neurosci. 6: 2403-2415.

Weiss, K. R., II. J. Chiel, and I. Kupfermann (1986c) Sensory function and gating of histaminergic neuron $\mathrm{C} 2$ in Aplysia. J. Neurosci. 6: 2416-2426.

Wendler, G. (1974) The influence of proprioceptive feedback on locust flight coordination. J. Comp. Physiol. 88: 173-200.

Wilson, D. M., and E. Gettrup (1963) A stretch reflex controlling wingbeat frequency in grasshoppers. J. Exp. Biol. 40: 171-185. 